\title{
Claritas rise, Mars: Pre-Tharsis magmatism?
}

James M. Dohm ${ }^{\text {a,b,*, Robert C. Anderson }}{ }^{\text {c,d }}$, Jean-Pierre Williams ${ }^{\text {d, Javier Ruiz }}{ }^{\text {e }}$, Patrick C. McGuire ${ }^{\mathrm{f}}$, Debra L. Buczkowski ${ }^{g}$, Ruye Wang ${ }^{h}$, Lucas Scharenbroich ${ }^{c}$, Trent M. Hare ${ }^{\mathrm{i}}$, J.E.P. Connerney ${ }^{\mathrm{j}}$, Victor R. Baker ${ }^{\text {a,b }}$, Shawn J. Wheelock ${ }^{\text {a }}$, Justin C. Ferris ${ }^{k}$, Hirdy Miyamoto ${ }^{1}$

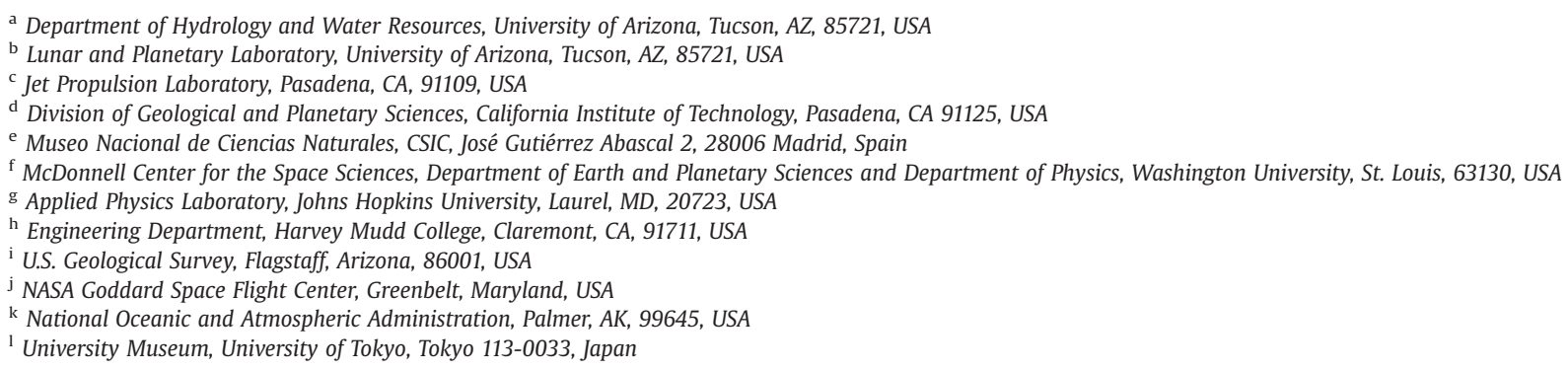

\section{A B S T R A C T}

Keywords:

Mars

Claritas rise

Tharsis

Claritas Fossae

Syria Planum

Thaumasia highlands

superplume

plume

tectonism

hydrothermal

dynamo

magnetosphere
Claritas rise is a prominent ancient (Noachian) center of tectonism identified through investigation of comprehensive paleotectonic information of the western hemisphere of Mars. This center is interpreted to be the result of magmatic-driven activity, including uplift and associated tectonism, as well as possible hydrothermal activity. Coupled with its ancient stratigraphy, high density of impact craters, and complex structure, a possible magnetic signature may indicate that it formed during an ancient period of Mars' evolution, such as when the dynamo was in operation. As Tharsis lacks magnetic signatures, Claritas rise may pre-date the development of Tharsis or mark incipient development, since some of the crustal materials underlying Tharsis and older parts of the magmatic complex, respectively, could have been highly resurfaced, destroying any remanent magnetism. Here, we detail the significant characteristics of the Claritas rise, and present a case for why it should be targeted by the Mars Odyssey, Mars Reconnaissance Orbiter, and Mars Express spacecrafts, as well as be considered as a prime target for future tier-scalable robotic reconnaissance.

\section{Introduction}

Mars has had an active and varied geologic history similar in many respects to that of the Earth, but its surface has been significantly less modified by global-scale erosional processes and plate tectonism, since at least the Late Noachian (Baker et al., 2007). Thus, a substantial archive of the paleotectonic history (a record of structural development through time) has been recorded in the crustal rocks. This record is particularly distinct in the western equatorial region where the five major stages of Tharsis-driven activity (Dohm et al., 2001a,b, 2007) contributed to the formation of both large and small extensional and contractional structures, including the vast canyon system, Valles Marineris (Dohm et al., 2009 this issue). Associated with the growth of Tharsis is an enormous radiating system of grabens, Claritas Fossae (the southern arm of the Tharsis axial trend of faults), which fans outward for thousands of kilometers from near the shield complex, Syria Planum, to the south (Figs. 1-3). Claritas Fossae is a significant recorder of Tharsis activity because it forms one of the densest, long-lived systems of faults and grabens in the western equatorial region (Dohm et al., 2001a,b). Even more intriguing is that parts of this distinct yet complex fault system may pre-date the origin or growth of Tharsis.

Noachian-Early Hesperian (stages 1-3 of Tharsis development; Dohm and Tanaka, 1999) tectonism associated with the early development of Tharsis, as well as pre-Tharsis activity, is much more complex, diverse, and dense when compared to its Late Hesperian and Amazonian 


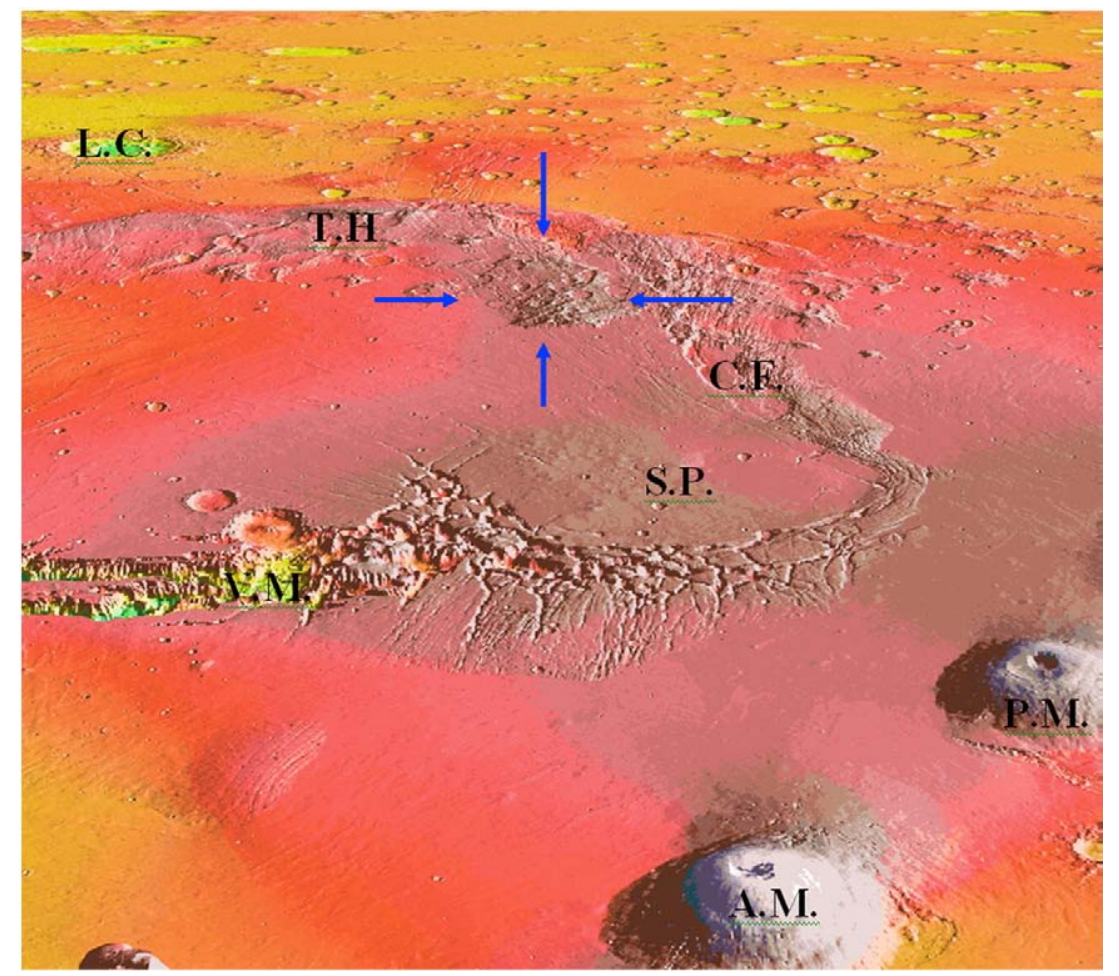

Fig. 1. 3D perspective image using MOLA topography, including an extreme 25× exaggeration, looking obliquely to the south across Ascraeus Mons (A.M.) and Pavonis Mons (P.M.), western margin of Valles Marineris (V.M.), Syria Planum (S.P.), Claritas Fossae (C.F.), Claritas rise (blue arrows), Thaumasia highlands mountain range, and Lowell impact crater (L.C.). Note that (1) in plan view, approximately $800 \mathrm{~km}$ separate the caldera complexes of A.M. and P.M. and the primary basin of Lowell impact crater is approximately 200 km, (2) the highly-deformed, rugged promontory of Claritas rise forms the northwest part of the ancient Thaumasia highlands mountain range, and (3) Claritas rise occurs on a complex rift and fault system, C.F., marking a major crustal/lithospheric weakness. (For interpretation of the references to color in this figure legend, the reader is referred to the web version of this article.)

(stages 4-5) development, when the giant shield volcanoes were forged (Anderson et al., 2001; Dohm et al., 2001a). The ancient Thaumasia highlands mountain range (Figs. 1 and 4), for example, which forms the southern margin of the Thaumasia plateau, records magnetic signatures, displays cuestas, hog backs, and valley networks, and is deformed by a complex structural fabric of extensional and contractional structures, including thrust faults (Dohm et al., 2001b). This ancient mountain range is therefore critical to assessing the early evolution of Mars (e.g., Baker et al., 2007). Here, the word 'ancient' will be taken to mean preand/or incipient Tharsis development, which includes activity associated with mountain building of the Thaumasia and Coprates rise mountain ranges (Fig. 4).

Another ancient feature critical to assessing the early evolution of Mars is the Claritas rise, a distinct promontory located to the south of Syria Planum along Claritas Fossae (Figs. 1-5). Similar to the rest of the Thaumasia highlands, it records rugged terrain, complex structure, and possibly a magnetic signature. It has been identified as a primary center of Noachian tectonism in the western hemisphere of Mars through the evaluation of more than 25,000 tectonic structures (including fault segments) in time and space using digital structural mapping, quantification, and statistical techniques (Anderson et al., 2001).

Critically, over eight hundred segments of faults are radial about the primary center (Anderson et al., 2001) (Fig. 6). These include faults that cut mountain-forming rock materials of the Thaumasia highlands but are onlapped by younger lava flows along the margin of the mountain range (Dohm et al., 2001b). Importantly, the fault segments could also be related to subsequent Tharsis activity such as the development of Syria Planum. This activity may include possible reactivation of older basement structures such as Claritas rise-centered faults. Claritas rise has been interpreted to be an ancient center of magmaticdriven activity, which includes uplift, tectonism, and possible hydro- thermal and volcanic activity (Dohm et al., 2001a; Schulze-Makuch et al., 2007), though some of the strain history could result from stresses indicative of loading at the surface from volcanic construction (thus, we refer generally to the Claritas rise as magmatic-driven). Possibly corresponding with a distinct magnetic signature (Fig. 7), it may mark activity when the magnetosophere was extant. Therefore, since Tharsis lacks detectable magnetic signatures, Claritas rise may mark either pre-Tharsis activity or incipient Tharsis development. The timing of the formation of Claritas rise in relation to the Tharsis magmatic complex is currently indeterminable, as older crustal materials and some of the older parts of the giant magmatic complex may have been highly resurfaced due to major stages of Tharsis activity (Dohm et al., 2001a,b), destroying any evidence of remanent magnetism (Connerney et al., 2001). In the following sections, we further describe the geologic and physiographic setting of the prominent Claritas rise, its significance based on geologic, paleotectonic, spectral, and geophysical information, and argue for further study due to its importance as presented in the following.

\section{Physiographic and paleotectonic setting of Claritas rise}

The Claritas rise and surrounding regions are marked by enormous rift systems and highly-deformed promontories (Figs. 1-5) interpreted to be basement complex (Scott and Tanaka, 1986). Claritas rise is itself a distinct, quasi-circular, rugged promontory located between the complex shield volcano of Syria Planum and the pre-Tharsis mountain range, Thaumasia highlands, along the Claritas Fossae. Claritas Fossae is a fault system that fans from near Syria Planum outward to the south (Figs. 3 and 6). Utilizing Geographic Information Systems (GIS), Dohm et al. $(1997,2001 \mathrm{~b})$ determined that Tharsis-associated faulting along Claritas Fossae commenced during the Early to Middle Noachian, declined during Late Noachian and Early Hesperian, and substantially 


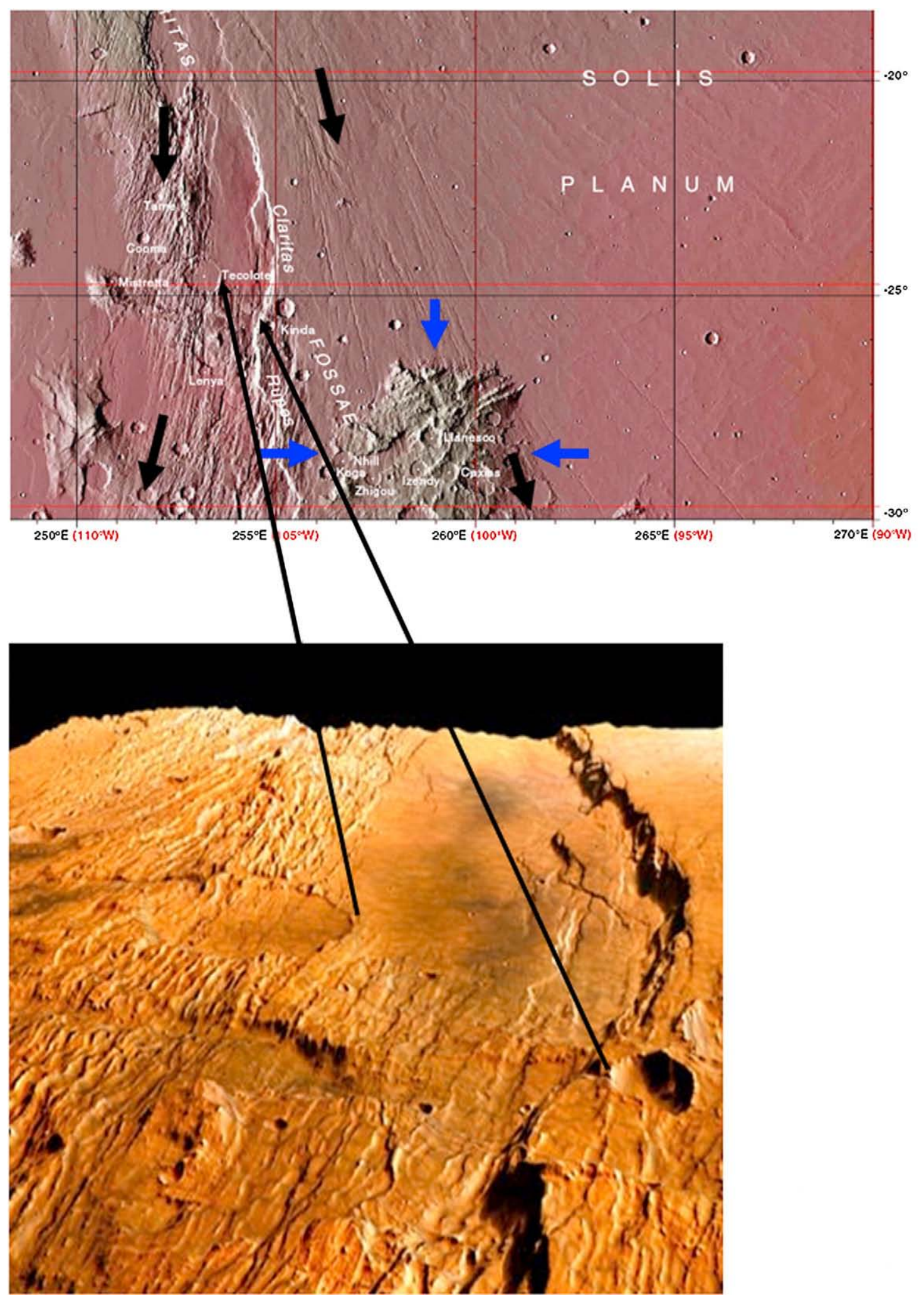

Fig. 2. (top) Part of the MC-17 Phoenicis quadrangle (Mars 1:5m MOLA; note that the black grid represents a revision of the grid system-see http://planetary names.wr.usgs.gov/ mgrid_mola.html for more information) showing faults of the Claritas Fossae fanning out to the south (black arrows) across the distinct promontory of Claritas rise (blue arrows). Also shown are the lava plains of Syria and Solis Planae that partly embay the Noachian materials of Claritas rise (also see Fig. 2B). Note that Claritas rise and other nearby rugged Noachian promontories, which are cut by faults of Claritas rise, display ancient, relatively-large tectonic structures of unknown origin (Dohm et al., 2001b). (bottom) 3-D oblique Mars Express image looking towards the north-northwest across the complex rift and fault system. The distance between the two impacts marking the western and eastern margins of the large rift (black arrows) is about $90 \mathrm{~km}$. (For interpretation of the references to color in this figure legend, the reader is referred to the web version of this article.)

diminished (an order of magnitude as compared to the Noachian) during the Late Hesperian and Early Amazonian. In addition to recording the development of parts of Tharsis (Dohm et al., 2007), such as the shield complex of Syria Planum, the Claritas rise comprises faults of the Claritas Fossae, as well as structures of indeterminate origin (Dohm et al., 2001b) (Fig. 5). The greatest percentage of faults 

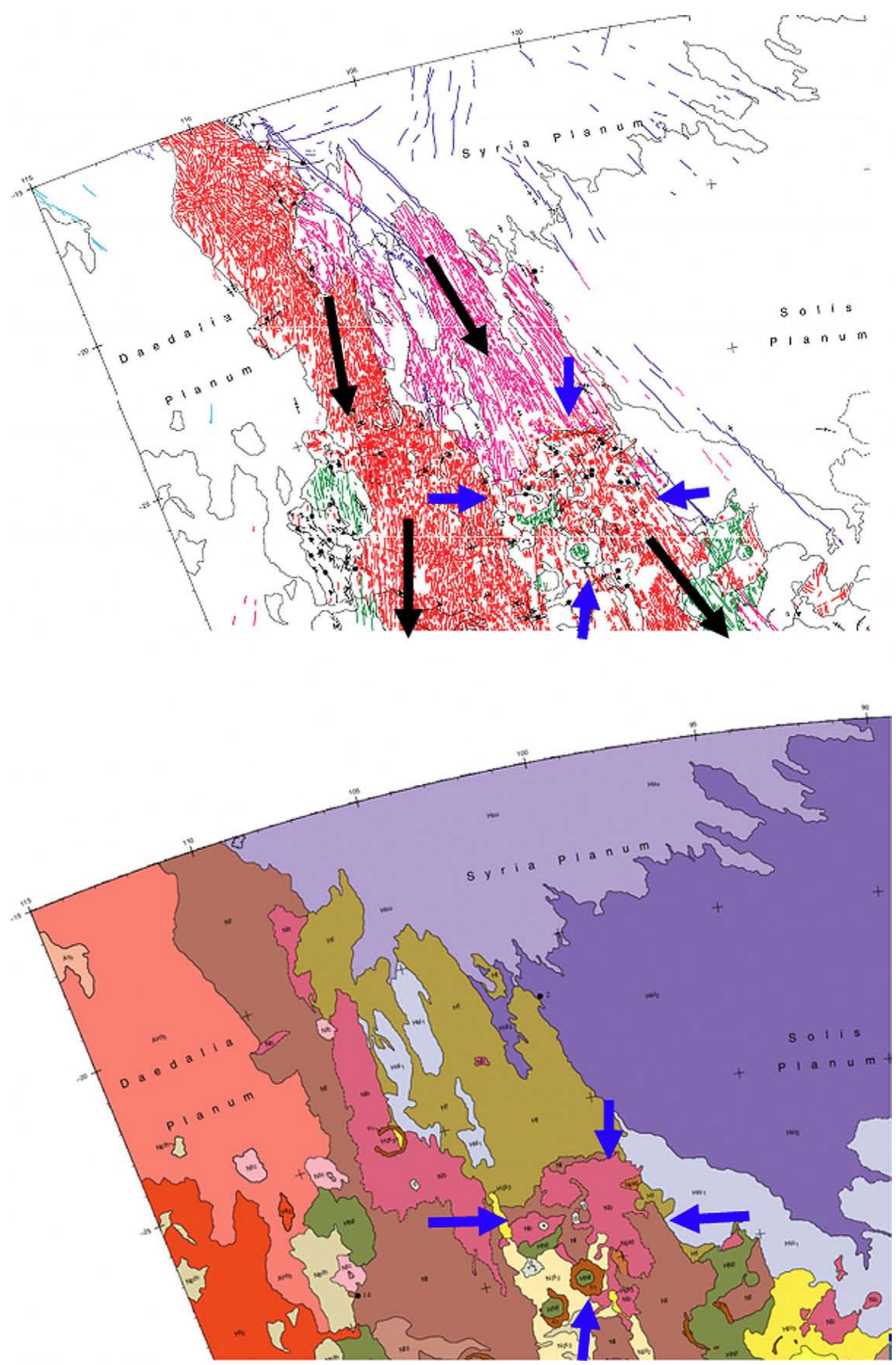

Fig. 3. (top) Similar to Fig. 1, but paleotectonic information of part of the Thaumasia region by Dohm et al. (2001b) using Viking data. The map records the distribution and relative ages of tectonic structures through five major stages of Tharsis development (stage 1-Noachian shown in red; stage 2-Late Noachian/Early Hesperian shown in green; stage 3-Early Hesperian shown in pink; stage 4-Late Hesperian/Early Hesperian shown in violet; stage 5-Amazonian shown in light blue). There is overlap in stage information due to crater statistical error. GIS-based calculations show an order magnitude greater fault and fault-length density in stage 1 materials when compared to stage 4 materials. (bottom) Similar to top image, but stratigraphic information showing Noachian materials of Claritas rise. Basement complex is among the interpretations for the promontory-forming rocks (a suite of mostly crystalline igneous and/or metamorphic rocks that generally underlies the sedimentary rock sequence). (For interpretation of the references to color in this figure legend, the reader is referred to the web version of this article.) 


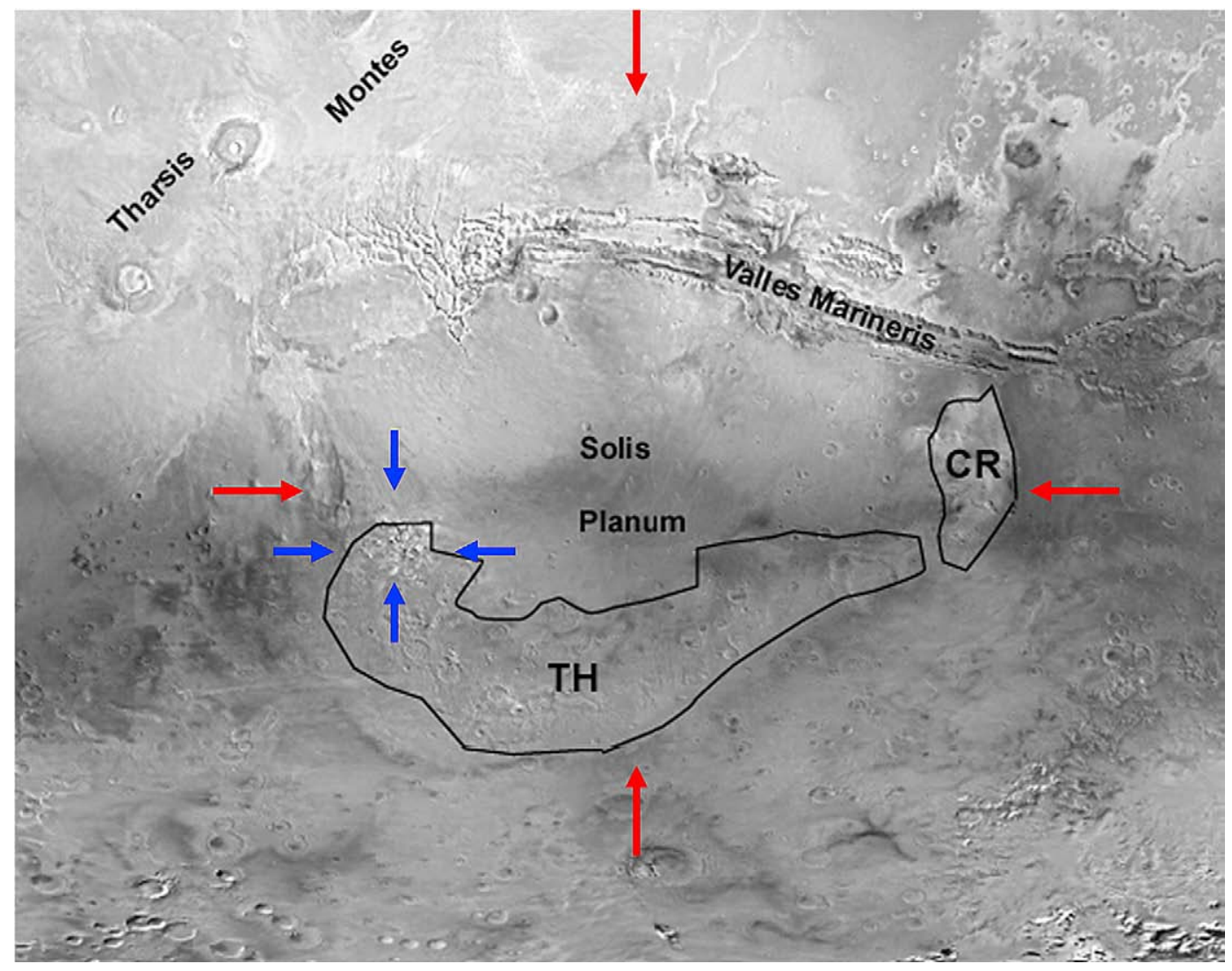

Fig. 4. Mars Digital Image Mosaic (MDIM) showing pre-Tharsis mountain ranges (Thaumasia highlands-TH and Coprates rise-CR), which exhibit magnetic signatures, complex structure, cuestas, and hogbacks. Also shown are Claritas rise (blue arrows), the lava plains of Solis Planum, the northeast -trending chain of giant shield volcanoes of Tharsis Montes (the caldera of southwestern-most, Arsia Mons, is about $120 \mathrm{~km}$ in diameter), and the vast canyon system of Valles Marineris, which would extend across the United States from Los Angeles to New York. The margins of the Thaumasia igneous plateau is also highlighted by red arrows. (For interpretation of the references to color in this figure legend, the reader is referred to the web version of this article.)

preserved in Noachian materials of the western hemisphere (e.g., including the ancient rocks of the Thaumasia highlands mountain range) radiate from Claritas rise (Anderson et al., 2001), making it a prominent Noachian center of tectonism. It is interpreted to result from magmatic-driven uplift and associated tectonism, as well as possible igneous and hydrothermal activity (Anderson et al., 2001; Dohm et al., 2001a,b,c), consistent with Viking-based mapping investigations which interpreted the rocks to be basement complex (Scott and Tanaka, 1986). A further assessment of the evolutional history of Claritas rise, specifically through its distinct spectroscopic and geophysical characteristics, will be discussed next.

\section{Geologic and mineralogic information of Claritas rise}

Ancient mountain ranges form the southern and southeastern margins of the Thaumasia plateau in the southeast part of Tharsis, Thaumasia highlands and Coprates rise, respectively (Figs. 4 and 8) (Dohm et al., 2001a,b). Information acquired from the Mars Express (MEX) spacecraft highlights the significance of the Thaumasia highlands mountain range as a window into an ancient phase of the evolution of Mars, which may include contractional deformation such as thrust faulting (Grott et al., 2007) related to orogenic activity (Anguita et al., 2006). Stratigraphic and cross-cutting relations, impact crater statistics, an order of magnitude greater density of tectonic structures in the mountains compared to the younger lava plains of the shield complex of Syria Planum, as well as distinct magnetic signatures indicate that the mountain ranges began to form before the shut down of the dynamo, prior to the evolution of Tharsis (Baker et al., 2007; Dohm et al., 2007). Forming the northwest part of the Thaumasia highlands is the highly rugged promontory of Claritas rise (Figs. 1 and 4). Determination of the mineralogic composition of these features has the potential to significantly improve understanding of the early geologic and geochemical evolution of Mars. The parent rock materials of these ancient features are unknown.

For example, are the rock compositions of the Thaumasia highland mountain range and Claritas rise distinct from Tharsis lavas? Is there a distinct rock record that is not obscured by Tharsis-era geologic activity, which dates back to at least the Middle Noachian epoch (Dohm et al., 2001a,b; Baker et al., 2007) or more than 3.7 Ga to present (Hartmann and Neukum, 2001)? More specifically, are there rocks other than volcanic compositions (e.g., other than basalt/basaltic-andesite), such as basement complex rocks (e.g., a suite of mostly crystalline igneous and/or metamorphic rocks that generally underlie the sedimentary rock sequence interpreted by Scott and Tanaka (1986))? In addition, is such a potential parent rock record free of fine-grained materials such as dust and thinly-layered secondary weathering products (e.g., see Squyres et al., 2004a,b for information on MER-based investigations that reveal secondary weathering rinds)? Moreover, is it possible that the parent rock, which may contribute to alluvial fan material along the margin of the Thaumasia highlands (Dohm and Tanaka, 1999), sufficiently exposed to be detected at the resolution of spectrometers onboard orbiting spacecraft, which include the Thermal Emission Spectrometer (TES) on the former Mars Global Surveyor (MGS), the Compact Reconnaissance Imaging Spectrometer for Mars (CRISM) on the Mars Reconnaissance Orbiter (MRO), and the Observatoire pour la Minéralogie, l'Eau, les Glaces, et l'Activité (OMEGA) imaging spectrometer on the Mars Express Orbiter?

Addressing whether these features are comprised of rocks other than volcanic is further prompted by similarities to terrestrial mountain 


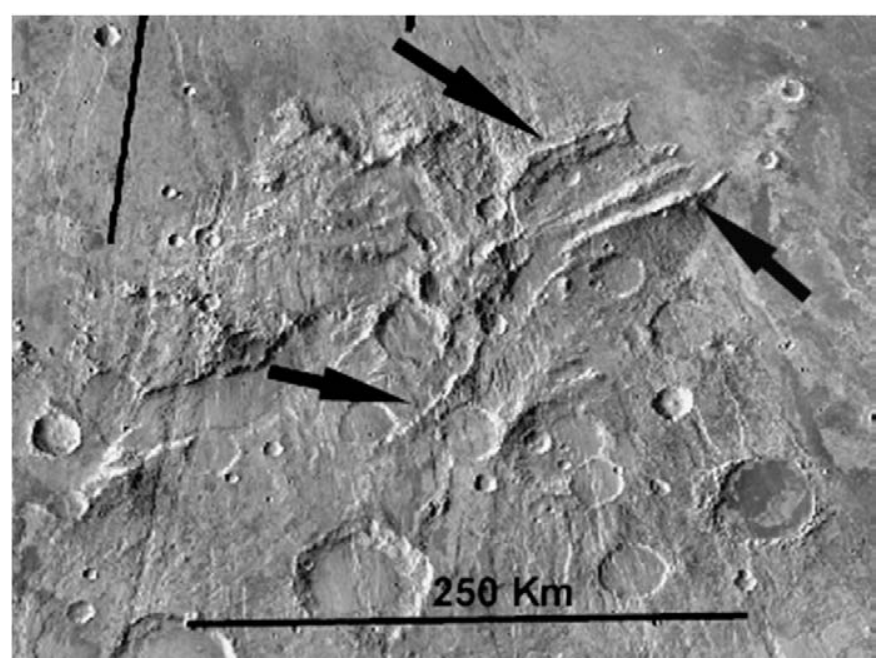

Fig. 5. Themis-IR daytime imagery showing Claritas rise, a distinct promontory marked by relatively-large (10 s to $100 \mathrm{~km}$-long) tectonic structures (arrows). Tectonic structures may include faults and fractures of complex rift systems related to extension (Dohm et al., 2001b), as well as features interpreted to represent contractional deformation such as folds (Anguita et al., 2006). In addition, some of the main structures are similar in appearance to those identified along some small volcanic rift zones in Tempe Fossae (Mège et al., 2003). ranges of diverse rock compositions (Dohm et al., 2001a,b). These include magnetic signatures (Acuña et al., 1999; Arkani-Hamed, 2003; Connerney et al., 2005), complex tectonic structures, cuestas, and hog backs. Individually, their implications may be minor, but taken collectively, they have a bearing on the current understanding of the early phase of the evolution of Mars (Dohm et al., 2001a,b, 2007; Baker et al., 2007).

Mars is commonly viewed as a monoplate planet, based largely on geophysical and geochemical arguments derived in part from the analysis of SNC meteorites (Halliday et al., 2001; Nimmo and Tanaka, 2005). Just as the ancient rock record may be obscured by mantling and secondary weathering processes, the SNC-associated sampling may only reveal a small fraction of the geologic and geochemical histories of Mars. Based on the petrology and cosmic ray exposure (CRE) ages of these meteorites, it is believed that they were 'launched' from eight distinct sites on the surface of the planet, most estimated to be within $20 \mathrm{Ma}$ (Eugster et al., 2006). This limited number of launch sites spread across the surface of Mars is a small sampling size of the planet, especially since it is relatively heterogeneous. Known rock compositions/types include basalt, basaltic andesite, hematite, quartz, andesite, phyllosilicates, sulfates, layered sedimentary deposits, etc. (e.g., Malin and Edgett, 2000; Bandfield et al., 2000; Christensen et al., 2000, 2001a,b, 2005; Rieder et al., 2004; Gendrin et al., 2005). Therefore, there is very little confidence that SNC meteorites provide an even and unbiased sampling of the Martian surface.

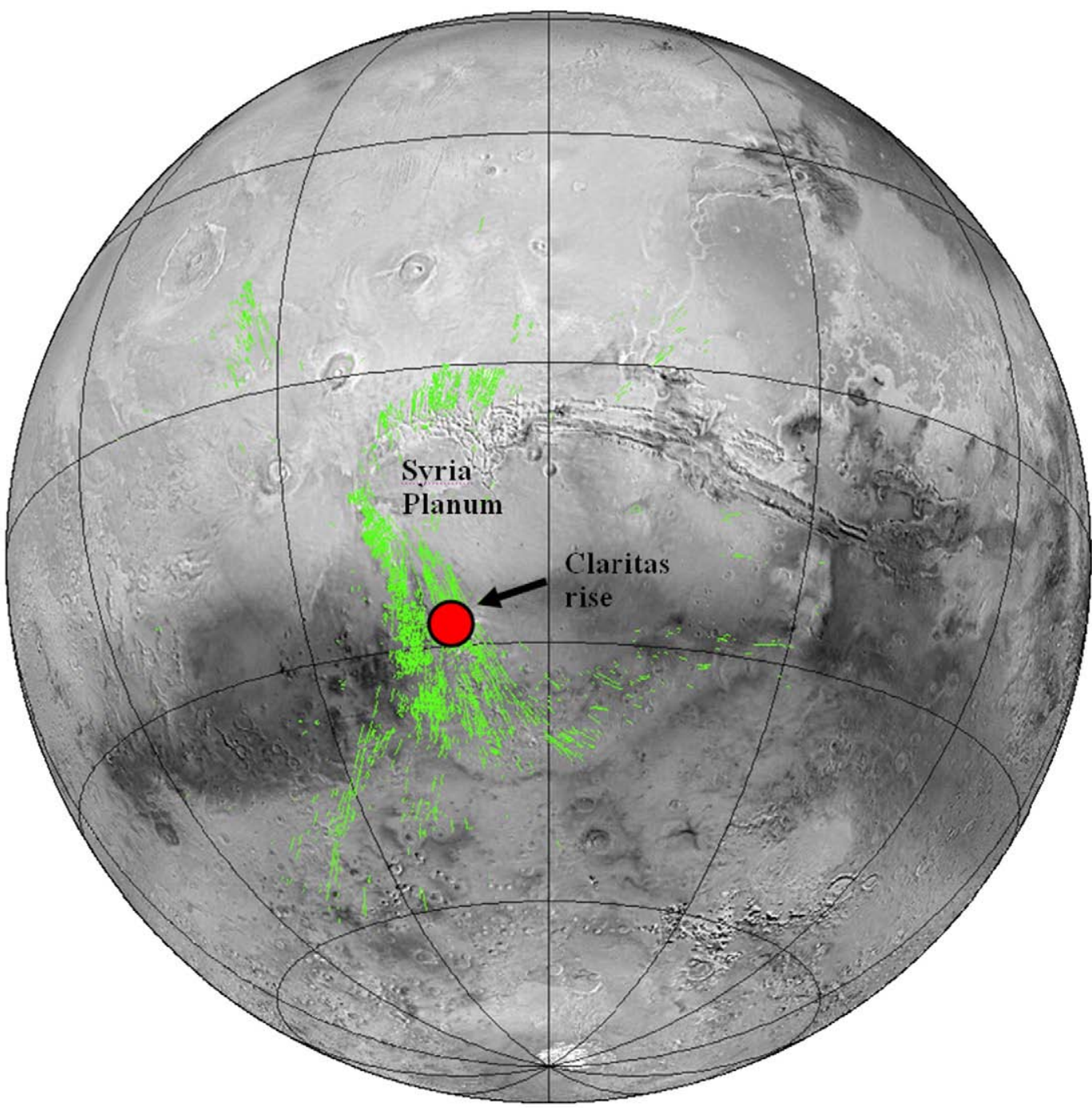

Fig. 6. Based from Anderson et al. (2001), more than 800 fault segments (green lines) point back to the Claritas rise. Note that other features such as the shield complex of Syria Planum contributed to the tectonic history of Claritas rise and surrounding terrains (Anderson et al., 2004). (For interpretation of the references to color in this figure legend, the reader is referred to the web version of this article.) 


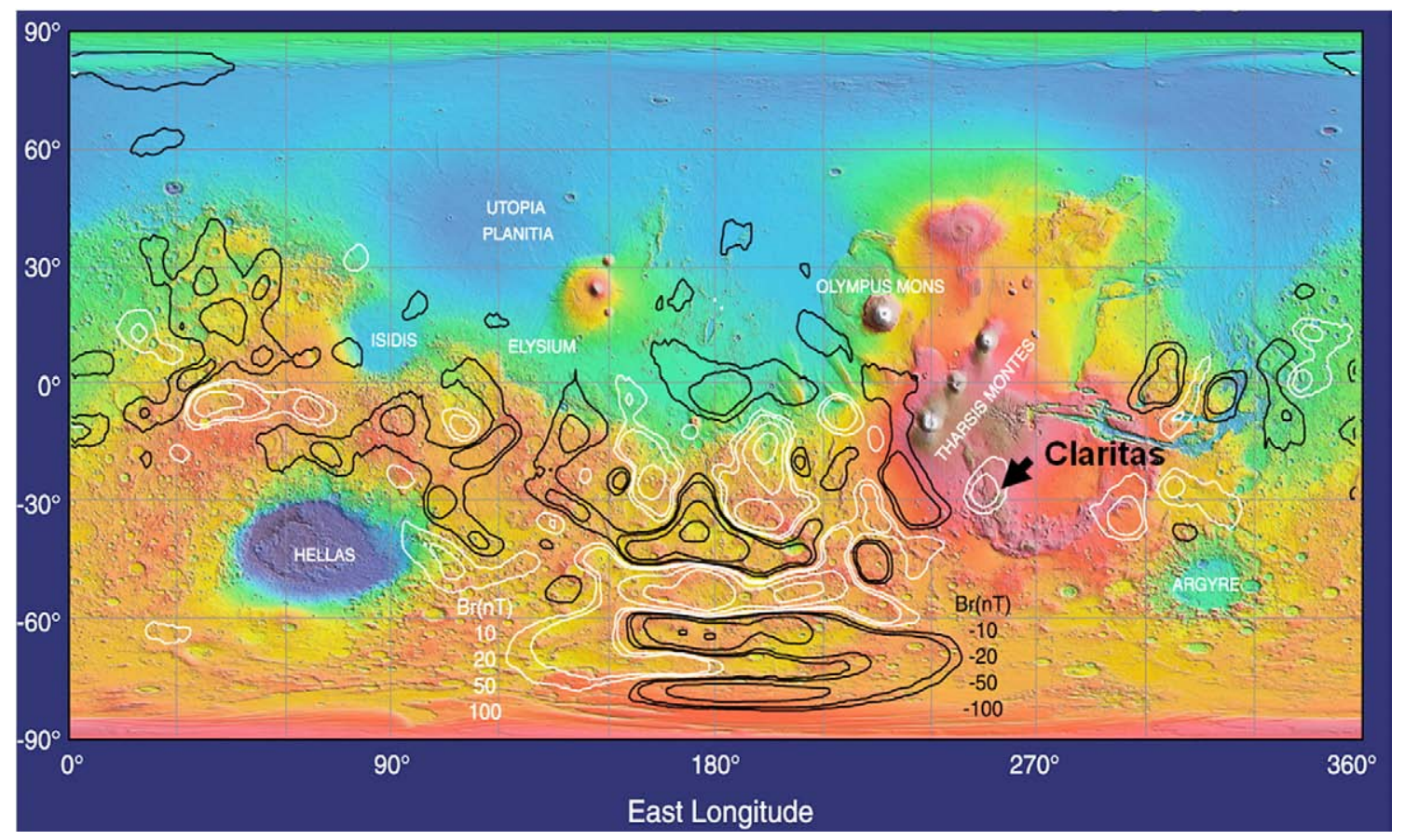

Fig. 7. MAG/ER data (Connerney et al., 2001) superposed on MOLA topography showing magnetic anomalies. Shown is the spatial association of Claritas with a magnetic anomaly. Note that it is difficult to determine whether the anomaly is genetically linked to the Claritas rise or if indeed there is an anomaly, since Tharsis may have demagnetized older crustal materials, and thus destroying magnetic information to the north, northeast, and west of Claritas rise skewing the data. (For interpretation of the references to color in this figure legend, the reader is referred to the web version of this article.)

Whether Claritas rise is other than basalt/basaltic andesite is a significant problem to address since it may record an ancient part of Mars' evolution, including hypothesized Earth-like evolutional phases such as plate tectonism (Sleep, 1994), particularly during its embryonic stages of evolution (Connerney et al., 1999; Dohm et al., 2002; Fairén et al., 2002; Connerney et al., 2005; Anguita et al., 2006; Baker et al., 2007).
Plate tectonics is invoked to account for many enigmatic features that mark the ancient geologic history of Mars. These include, but are not limited to: (1) the mountain ranges, Thaumasia highlands and Coprates rise, (2) large tectonic structures such as Tempe Mareotis Fossae and Phlegra Montes, and (3) geologic provinces such as Terra Cimmeria and Arabia Terra (Fig. 8) which record pronounced magnetic anomalies (Connerney et al., 1999; Dohm et al., 2002; Fairén et al.,

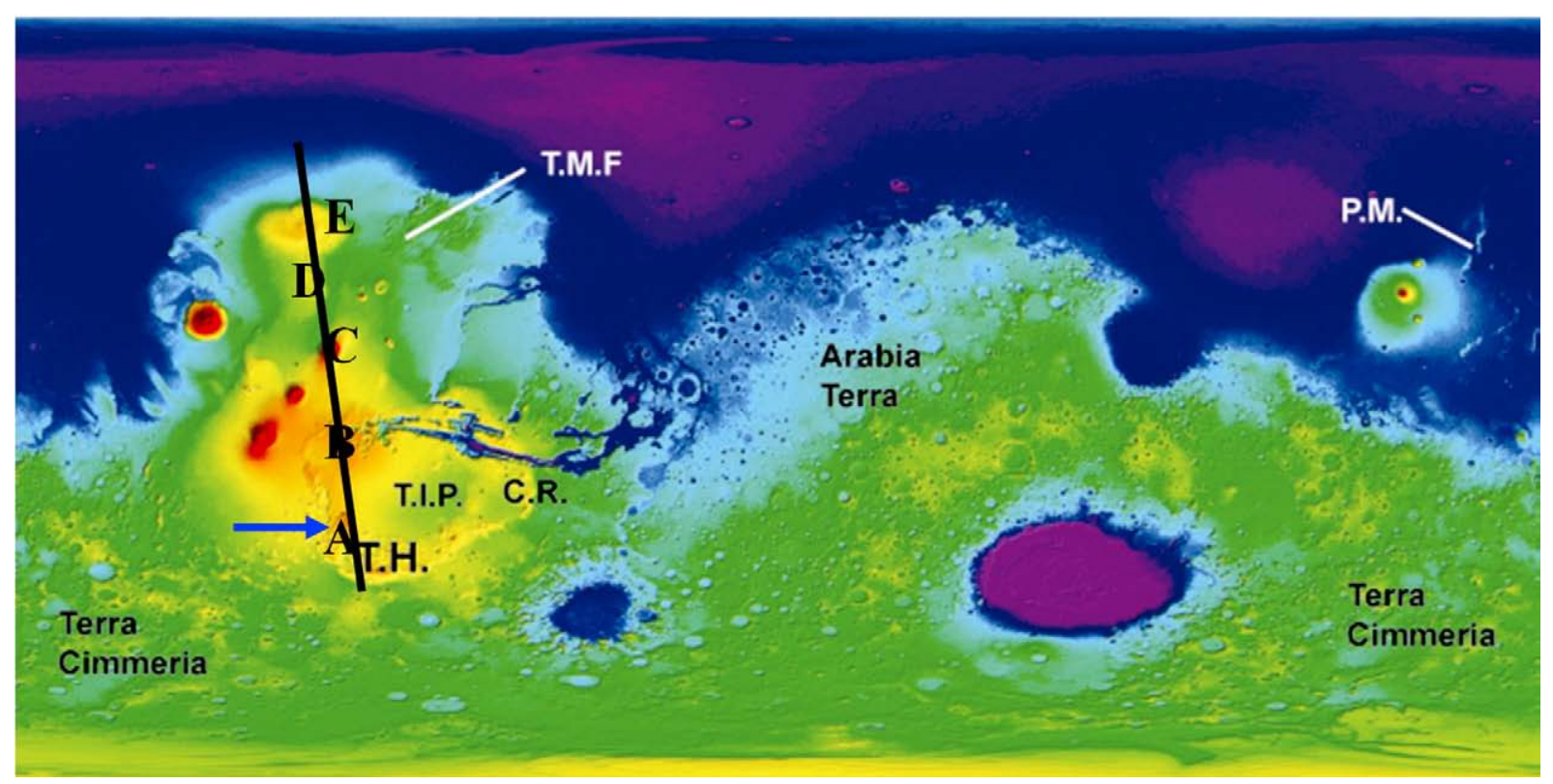

Fig. 8. MOLA-based map showing ancient features such as Claritas rise (blue arrow), Thaumasia highlands (T.H.) and Coprates rise (C.R.) mountain ranges, Phlegra Montes, Tempe Mareotis Fossae (T.M.F), and ancient geologic provinces such as Terra Cimmeria and Arabia Terra, all of which are considered as ancient markers of the early evolution of Mars. The "T" denoting Thaumasia highlands is approximately located at the central part of Figs. 9 and 10. Also shown is a north-northwest alignment of major features, including Claritas rise (A), Syria Planum (B), Ascraeus Mons (C), Ceraunius rise (D; please also see Anderson et al. (2001, 2004)), and Alba Patera (E). (For interpretation of the references to color in this figure legend, the reader is referred to the web version of this article.) 




Fig. 9. Map shows TES Types 1 and 2 plotted over a MOLA hillshade and a part of the USGS I-2605 map (Dohm et al., 2001b) (see corresponding Table 1). The TES data was classified by applying machine learning "untrained" techniques to Type 1 and Type 2 information (Bandfield et al., 2000; Wyatt and McSween, 2002; Ruff, 2003) using quality TES strips that cover part of the ancient Thaumasia highlands mountain range and younger plains-forming materials to the north and south of the mountain range. The geology has been reclassified into two types of materials: Ancient (mostly Early and Middle Noachian-stage 1 map units) and Young (Late Noachian and younger-stages 2-4 map units) based on (Dohm et al., 2001b). The histogram chart shows the density of the Types 1 and 2 TES data. This was calculated by dividing the individual TES points by the area of the ancient and young terrains. The density results clearly indicate that the mountain-forming materials are distinct from the plains-forming materials with more dominant Type 2 and Type 1 signatures, respectively. This is consistent with Viking-era geologic investigations (Scott and Tanaka, 1986; Dohm et al., 2001b). (For interpretation of the references to color in this figure legend, the reader is referred to the web version of this article.)

2002; Connerney et al., 2005; Dohm et al., 2005; Anguita et al., 2006; Baker et al., 2007).

\subsection{Thermal Emission Spectroscopy (TES) data of Claritas rise}

Included in the geologic investigation of Claritas rise, the TES data acquired by the MGS spacecraft were analyzed by machine learning methodologies using both supervised (classification) and unsupervised (clustering) techniques. Machine learning is a field of study concerning the design and development of algorithms to mimic human learning.
Here, algorithms were used for the analysis and interpretation of TES data, which has a spatial resolution approximating $\sim 3 \mathrm{~km} /$ pixel, covering the wavelength range from 6 to $50 \mu \mathrm{m}\left(\sim 1650-200 \mathrm{~cm}^{-1}\right)$. In general, there are two types of classification. First, unsupervised classification, or clustering analysis, assumes no prior knowledge of the data, and the structure of the data is automatically obtained by the algorithm. Second, supervised classification assumes and relies upon the availability of a small subset of data which are representative of a set of different types of classes of interest (e.g., different types of rock materials). During the training phase, the human experts manually 


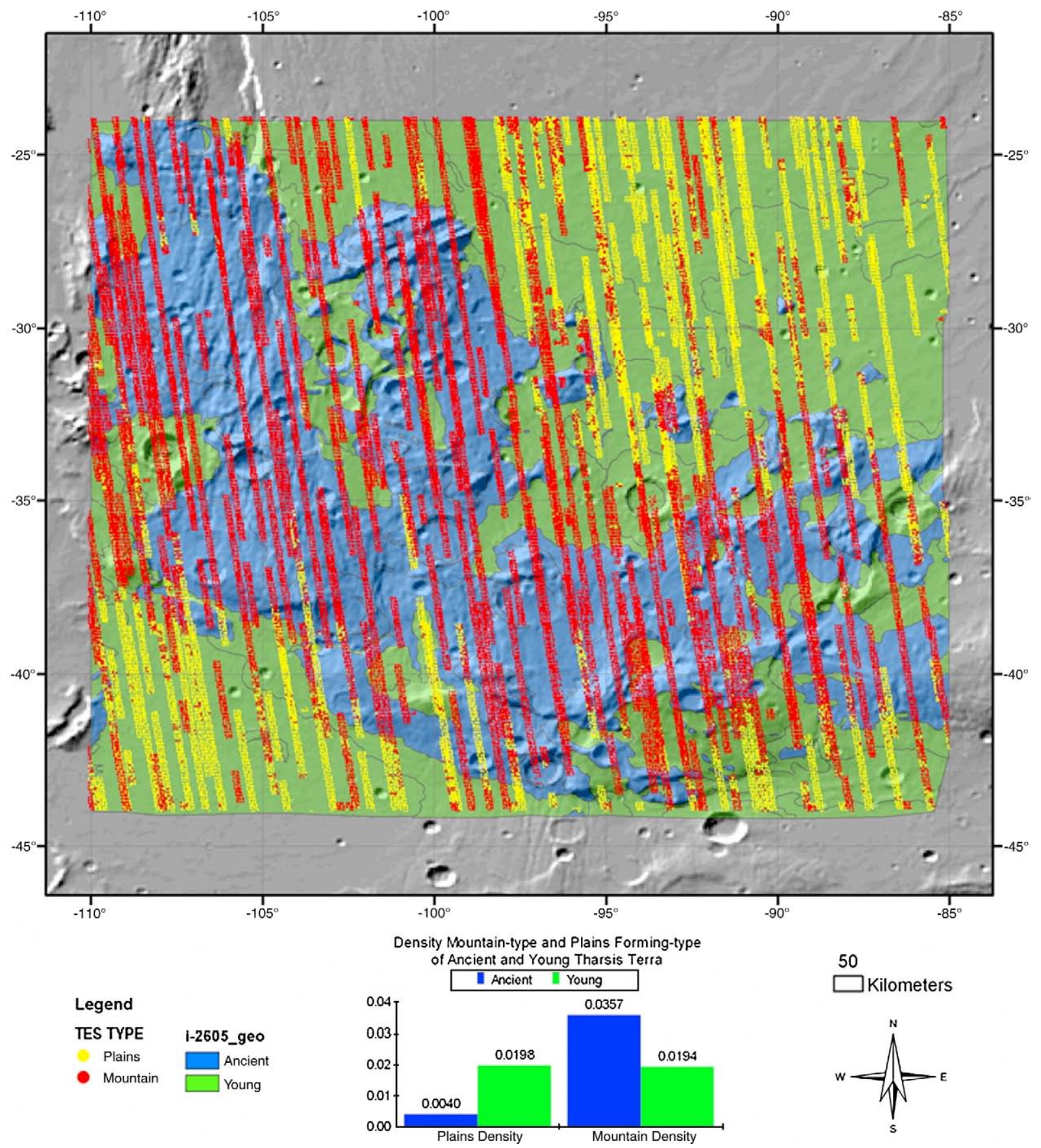

Fig. 10. Map shows mountain- and plains-forming-pixel types plotted over a MOLA hillshade and a part of the USGS I-2605 map (Dohm et al., 2001b) (see corresponding Table 1); the pixel location for each type was also based on the USGS I-2605 map). The TES data was classified by applying machine learning "trained" techniques to identify mountain-forming pixels from plains-forming pixels using quality TES strips that cover part of the ancient Thaumasia highlands mountain range and younger plains-forming materials to the north and south of the mountain range. The geology has been reclassified into two types of materials: Ancient (mostly Early and Middle Noachian-stage 1 map units) and Young (Late Noachian and younger-stages 2-4 map units) based on (Dohm et al., 2001b). The histogram chart shows the density of the mountain-forming and plains-forming TES-based information. This was calculated by dividing the number of individual TES pixels by the area of the ancient and young terrains. The longitudes are positive East. The density results clearly indicate that the mountain-forming materials are distinct from the plains-forming materials with corresponding mountain-forming and plains-type signatures, respectively. This is consistent with Viking-era geologic investigations (Scott and Tanaka, 1986; Dohm et al., 2001b). (For interpretation of the references to color in this figure legend, the reader is referred to the web version of this article.)

select a few small areas for each class of a known type of rock material. During the subsequent phase of automatic classification, the supervised algorithm assigns each of the pixels in the entire image to one of these classes, based on the comparison of the pixel's spectral signature and the average spectral signature of each class. At the end of this process, the entire region covered by the image is classified into a set of subregions, each representing a particular type of rock material.

To interpret the TES information, various clustering and classification algorithms have been applied to the pixels of these hyperspectral data. First, a spectral unmixing algorithm was used to find the abundances of a set of minerals, endmembers, expected to be present in each pixel of the TES data. In addition, unsupervised methods were used to carry out clustering analysis of all pixels based on their spectral profiles. The underlying structure of the data is automatically discovered during the clustering process. Second, supervised methods such as maximum likelihood classification, support vector machine, and Gaussian processing classification were used to classify the pixels in the TES data into two distinct categories of rock materials based on a 
Table 1

Corresponding with Fig. 9, the TES data was classified by applying machine learning to Type 1 and Type 2 end member information of Bandfield et al. (2000) and Bandfield and Smith (2003) by selecting pixels of quality TES strips that occur in the ancient mountain-building materials and younger plains-forming materials.

\begin{tabular}{lllll}
\hline Geologic type & Total area $\mathrm{km}^{2}$ & Total TES-type 1 pixels & Total TES-type 2 pixels & Density-TES type 1 \\
\hline Ancient & $631,718.96$ & 7095 & 19,017 & 0.0112 \\
Young & $819,600.71$ & 23,165 & 10,862 & 0.0301 \\
\hline
\end{tabular}

The geology has been reclassified into two units: Ancient (mostly Early and Middle Noachian-stage 1 map units) and Young (Late Noachian and younger-stages $2-4$ map units) based on Dohm et al. (2001b). The density results clearly indicate that the mountain-forming materials are distinct from the plains-forming materials with more dominant Type 2 and Type 1 signatures, respectively. This is consistent with Viking-era geologic investigations (Scott and Tanaka, 1986; Dohm et al., 2001b).

small number of training samples. The two types of training samples were the younger (Hesperian) lava plains-forming materials (e.g., Syria and Solis Planae) and ancient (Noachian) Thaumasia highlands mountain range-forming rock materials based on the geologic map information of Dohm et al. (2001b).

Specifically, canonical spectral endmembers representing atmospheric contributions (Bandfield and Smith, 2003), as well as surface types and pure mineral endmembers from the Arizona State University (ASU) Spectral Library (e.g., Bandfield et al., 2000; Christensen et al., 2000; Smith et al., 2000; Wyatt and McSween, 2002; Bandfield and Smith, 2003; Ruff, 2003), were used for the unsupervised clustering investigation. The endmembers used in the analysis included: Type I (basaltic endmembers)-Anorthite, Augite, Bytownite, Fayalite, Forsterite, and Labradorite, and Type II (granite-granodirite endmembers)Albite, Anorthoclase, Biotite, Microcline, Muscovite, Oligoclase, and Quartz. To determine whether there are distinctions in spectral signatures among the ancient mountain-forming materials of Thaumasia highlands, which includes Claritas rise, and the younger lava plains of the complex shield volcano (e.g., Syria and Solis Planae; Dohm et al., 2001a,b; Anderson et al., 2004), our approach included: (1) selecting "quality" tracks of TES data that have the least contributions from clouds, atmospheric and surface dust, or noise for comprehensive analysis, (2) applying unsupervised and supervised techniques to the "quality" tracks of TES data to visualize whether there is a spectral distinction between the ancient mountain-building materials and plains-forming materials, (3) separating out the older mountain-forming materials from relatively young plains-forming materials based on published geologic information using Geographic Information Systems (GIS) in order to couple these data with the machine learning-based results, and (4) quantifying the comparison among the machine learning-based results and the published geologic information of Dohm et al. (2001b). This includes determining the density of untrained Type 1 and Type 2 pixels and trained mountain-forming and plains-forming pixels (e.g., total amount of pixels of a specific type divided by the total area of either mountain-forming or plains-forming materials) (Figs. 9 and 10 and corresponding Tables 1 and 2). Area calculations for the two types of geologic units were computed using an equal-area sinusoidal projection.

The density results clearly indicate that the mountain-forming materials are distinct from the plains-forming materials with more dominant Type 2 and mountain-type for the ancient mountain-forming materials of the Thaumasia highlands mountain range and Type 1 and plains-forming type for the plains-forming materials, respectively. This is consistent with Viking-era geologic investigations (Scott and Tanaka, 1986; Dohm et al., 2001b), which indicated that the mountains could be comprised of diverse rock materials such as basement complex and the plains-forming materials being mostly composed of basaltic lava flows. Those pixels that do not show such a correspondence could be explained by multiple factors. There may be atmospheric obscuration and dust loading in some locations. Alternatively, materials shed from the prominent mountains may create alluvial fan materials comprised of both mountain-forming materials and plains-forming materials, lateral and vertical variations in the mantles may obscure bedrock, and younger volcanoes and lava flows occur in the mountain range (Dohm et al., 2001b).

The results clearly indicate that there is a spectral distinction between the two types of materials. What does the distinction mean? Clearly from the results, at the very least, we can say that the Thaumasia highlands mountain range comprises a greater diversity of rocks than just basalt-basaltic andesite. But can we properly identify the rock types that compose the mountain-forming materials with existing orbital platforms?

Next, we will examine recently acquired CRISM data, which provides hyperspectral observations with a spatial resolution approximating $\sim 18 \mathrm{~m} /$ pixel using 544 spectral channels, as well as multispectral mapping strips with lower spatial resolution ( $200 \mathrm{~m} /$ pixel $)$ using 72 spectral channels (Murchie et al., 2007a,b, in press), to see whether this particular spectroscopic platform can reveal the composition of the rock-forming materials of Claritas rise.

\subsection{CRISM analysis of the Claritas rise-forming rock materials}

OMEGA and CRISM have both identified a significant number of locations of hydrated sulfates (Bibring et al., 2005; Gendrin et al., 2005; Murchie et al., in press) and hydrated phyllosilicates (Bibring et al., 2005; Poulet et al., 2005; Milliken et al., 2008b; Bishop et al., 2007; Mustard et al., 2007; Bishop et al., 2008a,b; McKeown et al., 2008; Mustard et al., 2008) on the Martian surface, as well as other hydrated minerals, such as hydrated silica (Milliken et al., 2008a,b; Bishop et al., 2008a). One such locality is the Claritas rise. Fe/Mg-rich hydrated phyllosilicates, as well as olivine and low-calcium pyroxene minerals, have been revealed through preliminary reconnaissance of a CRISM image, which covers part of the rise (Fig. 11).

We note that the BD2300-indicator (Pelkey et al., 2007; indicative of possible Fe/Mg-rich hydrated phyllosilicates), highlighted in red, is particularly distinct along the crest of promontories and some of the large lineaments interpreted to be faults, possibly cropping out of the hillslopes (e.g., centers of the red, green, and blue boxes in Fig. 11). In addition, it appears to be distributed in the central area of the image

Table 2

Corresponding with Fig. 10, the TES data was classified through machine learning by selecting pixels of quality TES strips that occur in the ancient mountain-building materials and younger plains-forming materials.

\begin{tabular}{lllll}
\hline Geologic type & Total area $\mathrm{km}^{2}$ & $\begin{array}{l}\text { Total plains-forming } \\
\text { type pixel }\end{array}$ & $\begin{array}{l}\text { Total mountain-forming } \\
\text { type pixels }\end{array}$ & $\begin{array}{l}\text { Density-total plains-forming } \\
\text { type pixels }\end{array}$ \\
\hline Ancient & $631,718.96$ & 2505 & 22,537 & $\begin{array}{l}\text { Density-total mountain-forming } \\
\text { type pixels }\end{array}$ \\
Young & $819,600.71$ & 16,260 & 15,886 & 0.0040 \\
\hline
\end{tabular}

The geology has been reclassified into two units: Ancient (mostly Early and Middle Noachian-stage 1 map units) and Young (Late Noachian and younger-stages 2-4 map units) based on (Dohm et al., 2001b). The density results clearly indicate that the mountain-forming materials are distinct from the plains-forming materials with more dominant mountain-type and plains-forming-type signatures, respectively. This is consistent with Viking-era geologic investigations, interpreted to be largely basement complex and basaltic lava flows, respectively, based on Viking-era geologic investigations (Scott and Tanaka, 1986; Dohm et al., 2001b). 
occurring among distinct faults and rugged terrain. Similar to the BD2300-indicator, the low-calcium pyroxene index (LCPINDEX) appears to be concentrated along the flanks of promontories and fault scarps. The olivine index (OLINDEX), highlighted in green, on the other hand, is widespread across the image. The LCP summary parameters are correlated to shadowed regions. There is obviously pyroxene and olivine in the region based on the spectra, but the pattern of the summary parameters (green vs. blue) may also be an albedo effect.

We choose three locations of interest based upon the spectral summary browse image, primarily by using the BD2300-indicator (Pelkey et al., 2007) (Fig. 11), and we show atmospherically- and photometrically-corrected spectra (Langevin et al., 2005) for these
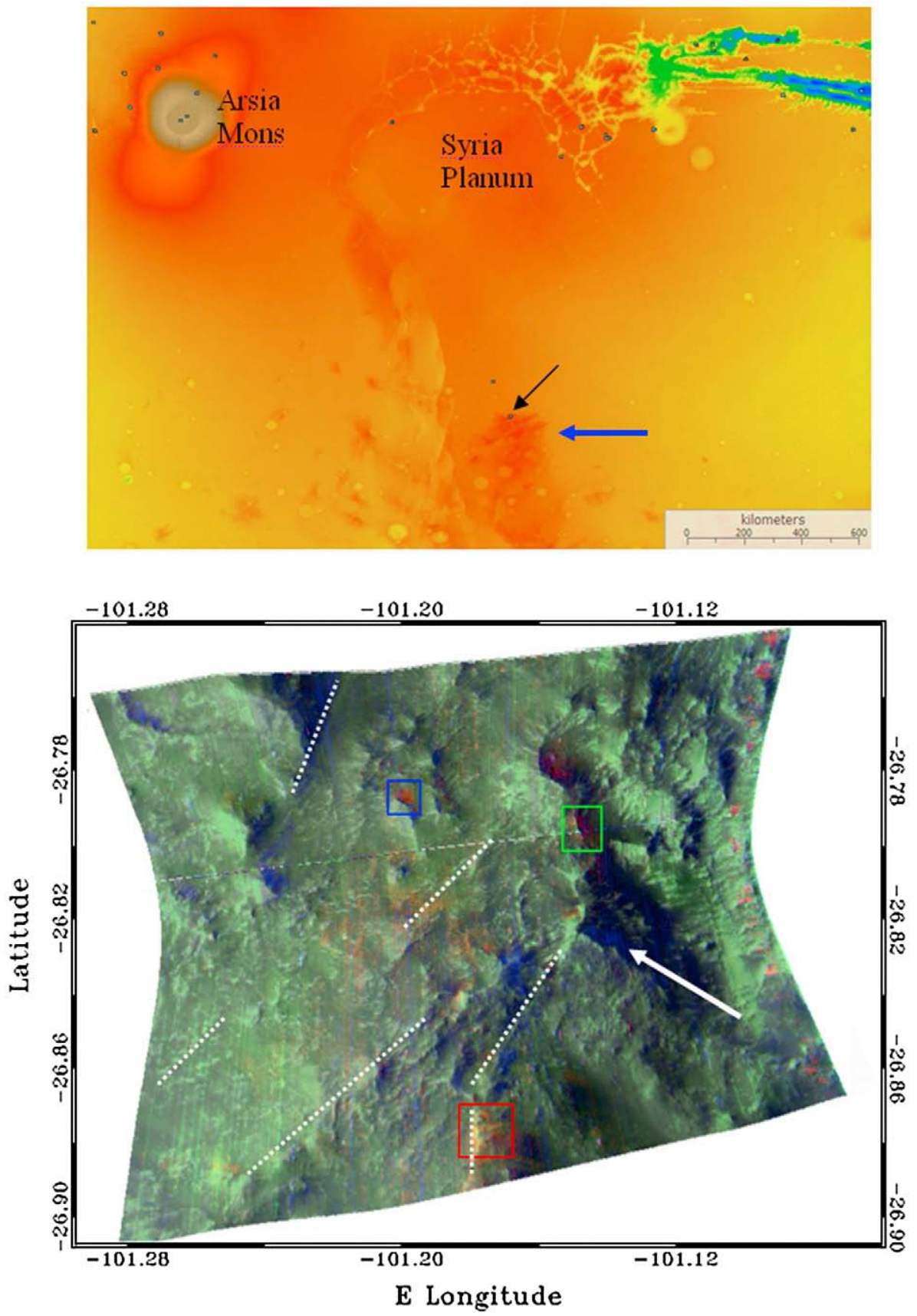

Fig. 11. (top) Index map showing the location of CRISM browse image FRT0000634B (black arrow) of Claritas rise (blue arrow) with respect to Arsia Mons and Syria Planum. (bottom) CRISM spectral summary browse image FRT0000634B of 'Llanesco Cexias northwest', in Claritas rise, acquired on June 6, 2007 at a solar longitude $\left(L_{s}\right)$ of $256.2^{\circ}$ and a solar incidence angle of $43.2^{\circ}$. The width of this image is $10-12 \mathrm{~km}$. The spectral summary browse image (red=BD2300=indicator of material rich in hydrated iron/magnesium phyllosilicates; green $=$ OLINDEX $=$ indicator of olivine-rich material; blue $=$ LCPINDEX=indicator of material rich in low-calcium pyroxene) is transparently overlain on a grey-scale map of $1.3 \mu \mathrm{m}$ reflectance. The stretch on the summary parameters was red (BD2300) 0-0.02; green (OLINDEX) 0-0.10; blue (LCP) $0-0.05$. The three squares correspond to the locations of the spectral ratios in Fig. 12; the color of the square matches the color of the spectra shown in Fig. 12. A ratio of the spectrum from the center of the red square to a spectrally-bland region in the same vertical columns of the detector is also shown in Fig. 13. The default volcano-scan correction along with the default Lambertian cos( $i)$ correction was applied prior to computing the spectral summary browse image as well as the underlying $1.3 \mu \mathrm{m}$ reflectance image. The vertically-intermittent purple-colored banding on the right side of this browse image is limited to a few vertical columns of the CRISM detector and is therefore an artifact. Note that promontories (white arrow pointing to the largest of at least 3 ) and some of the lineaments (dashed white lines-interpreted to be faults) are highlighted by both red and blue patterns while the green pattern is widely distributed in the image (some of the lineaments appear to be mantled by the green-highlighted materials). (For interpretation of the references to color in this figure legend, the reader is referred to the web version of this article.) 


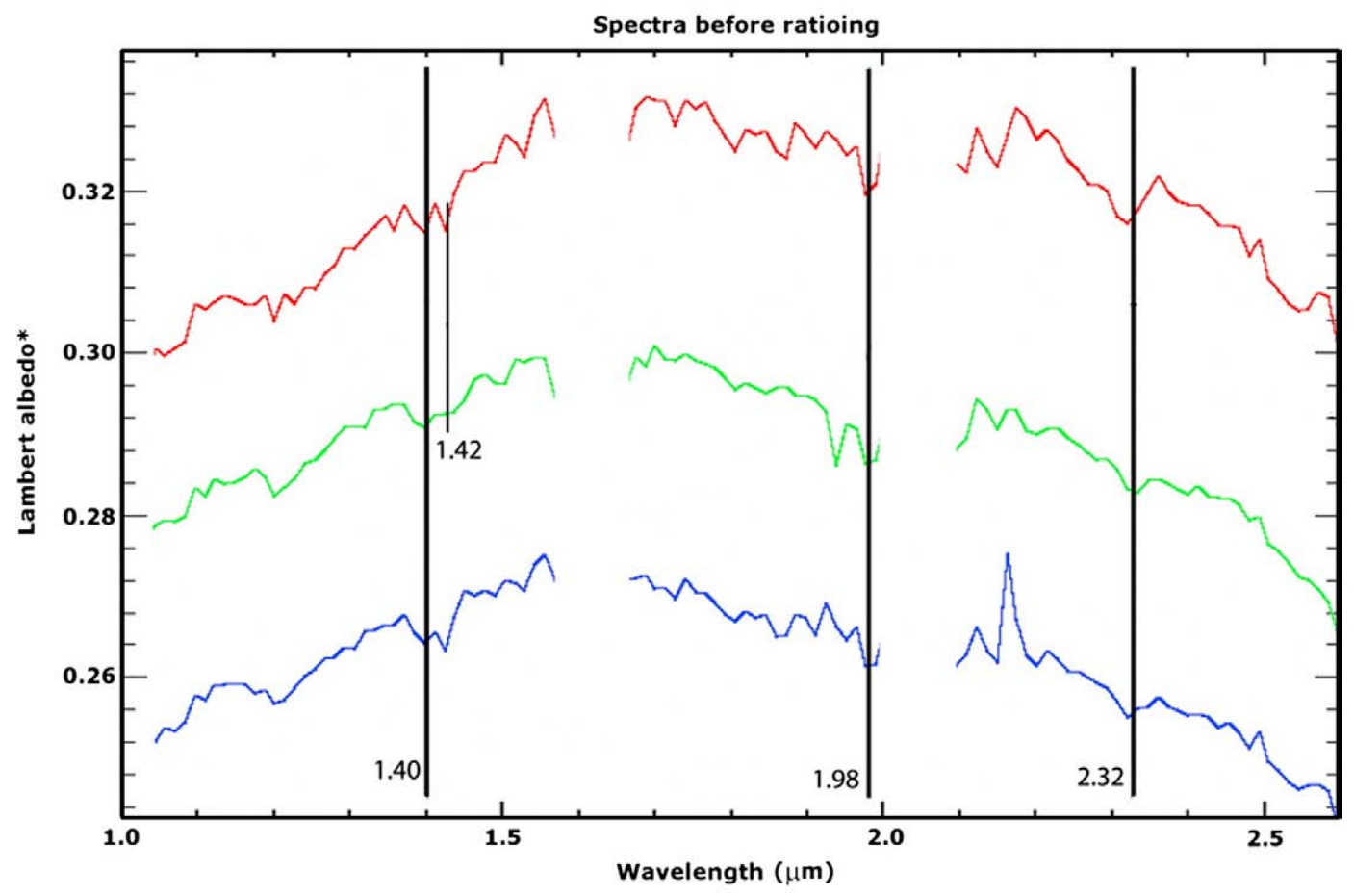

Fig. 12. Atmospherically- and photometrically-corrected spectra for CRISM image FRT0000634B of 'Llanesco Cexias northwest', in Claritas rise. The spectra were averaged over $3 \times 3$ pixels $^{2}$ regions. The locations of the spectra are at the centers of the correspondingly-colored squares in Fig. 11. The solid vertical lines are for guiding the eye, for assessing the absorptions at $1.4 \mu \mathrm{m}, 1.42 \mu \mathrm{m}, 1.98 \mu \mathrm{m}$, and $2.32 \mu \mathrm{m}$. For clarity, we do not show here the data near the boundary of the VNIR and IR detector and near the filter boundary at $1.6 \mu \mathrm{m}$, nor in the atmospheric gas-bands from 2.0-2.1 $\mu \mathrm{m}$. The default volcano-scan along with the default Lambertian cos( $i$ ) correction was applied prior to computing the spectra, but no correction for aerosols has been applied.

locations in Fig. 12. A spectral ratio of the spectrum from the center of the red square in Fig. 11 is shown in Fig. 13, relative to a bland area of the image in the same detector columns as the interest point.

We note absorptions in the spectral ratio at $1.4 \mu \mathrm{m}, 1.9 \mu \mathrm{m}, 2.32 \mu \mathrm{m}$, and near $2.5 \mu \mathrm{m}$. Absorptions at $1.4 \mu \mathrm{m}, 1.9 \mu \mathrm{m}$, and $2.32 \mu \mathrm{m}$ match the spectra of smectites and other hydrated phyllosilicates which contain $\mathrm{Mg}$ or Fe as measured for terrestrial samples. The identification of the key absorptions matching phyllosilicates is possible even with the unratioed spectra in Fig. 12, though the ratioing for one of the three spectra in Fig. 13 makes this perhaps more evident. The very narrow dips in the spectrum in Fig. 13 at $1.5 \mu \mathrm{m}$ and at $1.8 \mu \mathrm{m}$ are likely due to noise in the detector, since they are constrained to one channel each. The absorption at $2.1 \mu \mathrm{m}$ in Fig. 13 is likely a real absorption, though it is in the 1.9-2.1 $\mu \mathrm{m}$ range, which can be affected by inaccurate correction for

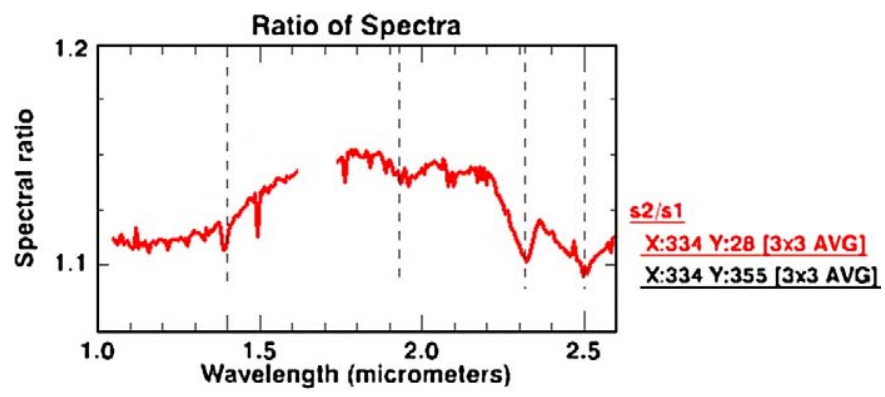

Fig. 13. Spectral ratio for CRISM image FRT0000634B of Llanesco Cexias northwest in Claritas rise. The spectrum was averaged over a $3 \times 3$ pixels $^{2}$ region. The location of this spectrum is indicated by the red square in Fig. 11, and the colored detector coordinates in the legend of this sub-figure. The uncolored entry in the legend of this sub-figure is the location of the reference spectra for computing the spectral ratio. The dashed vertical lines are for guiding the eye, for assessing the absorptions at $1.4 \mu \mathrm{m}, 1.92 \mu \mathrm{m}, 2.32 \mu \mathrm{m}$, and $2.5 \mu \mathrm{m}$. For clarity, we do not show here the data near the boundary of the VNIR and IR detector and near the filter boundary at $1.6 \mu \mathrm{m}$. (For interpretation of the references to color in this figure legend, the reader is referred to the web version of this article.) carbon dioxide in the atmosphere. The positions of the absorptions give a reasonable spectral match in both the spectra and in the spectral ratios with phyllosilicates rich in iron and/or magnesium. Though we do not match the spectrum in the CRISM image of Claritas rise (FRT0000634B) in Fig. 13 to a particular phyllosilicate, Ehlmann et al. (2009a) recently identified it as 'serpentine', along with further identifications of serpentine in the Nili Fossae region (Ehlmann et al., 2009b).

The CRISM image (FRT0000634B), located at 26.82S, 101.20W within the north-central part of the Claritas rise, displays distinct promontories, lineaments interpreted to be faults, and rugged plains. Distinct red and blue highlights often correspond with the crest of promontories or fault scarps. Though, red patterns are also distributed among faulted rugged plains in the central part of the image. On the other hand, green patterns are widely distributed across the image. The CRISM spectral signatures could mark local hydrated iron/ magnesium phyllosilicates (red patterns) and rock materials rich in low-calcium pyroxene (blue patterns) outcropping locally (in situ materials), possibly mantled in many places by olivine-rich materials (e.g., wind blown fine-grained, olivine-rich basaltic materials and/or air fall deposits from Tharsis). The olivine-rich materials (green pattern) may also occur locally (in situ).

This CRISM image (FRT0000634B) is the only CRISM image in the Claritas rise region that has a phyllosilicate signature within the set of CRISM images acquired and available in the Planetary Data System (PDS) as of May 2008. One other CRISM image in the Claritas rise region (FRT00008120) also has signatures of phyllosilicates, but we defer the analysis of this image to future work, since it has become publicly available through the PDS only after this paper was submitted.

In order to get a broader perspective about both the existence and origin of phyllosilicates in the region of CRISM image FRT0000634B, it would be useful to study OMEGA hyperspectral data of this location, albeit at lower spatial resolution. There is currently (January 2009) no OMEGA data that covers this location. We have performed a cursory reconnaissance of a nearby location within Claritas rise using OMEGA 
data (Orb519_1), and there may be phyllosilicates present here, but at a low level (band depths at a wavelength of $2.29 \mu \mathrm{m}$ range from 0.01-0.02) at certain locations within this mapping strip of OMEGA. More work is warranted to confirm this and to understand fully the OMEGA data at regions near the CRISM detection of phyllosilicates in Claritas rise.

Outcrops of CRISM-identified Fe/Mg-rich hydrated phyllosilicates, locally exposed and distributed by wind and gravity-driven processes along fault scarps and at the crest of promontories (poking up through fine-grained mantles of olivine-rich basaltic rock materials), are consistent with the TES investigation that shows a spectral distinction among the ancient (Noachian) rock materials of Claritas rise and other parts of the ancient Thaumasia highlands mountain range and the relatively young (Early Hesperian and younger) lava plains of Syria and Solis Planae identified from detailed geologic mapping (Dohm and Tanaka, 1999; Dohm et al., 2001b). In addition, the identification of Fe/ Mg-rich hydrated phyllosilicates exposed along faults using CRISM supports the hypothesis that (mafic) phyllosilicates can be observed on Mars at locations where tectonism interacts with water (e.g., Mustard et al., 2007).

On Earth, hydrated iron/magnesium phyllosilicates are observed in environments which include hydrothermal activity. An example is the hydrothermal alteration of the country rock related to intrusive activity observed in France (e.g., Merceron et al., 1992). The CRISM-based identification of $\mathrm{Fe} / \mathrm{Mg}$-rich hydrated phyllosilicates, as part of the suite of potential rock materials that form the Claritas rise, is consistent with MEX OMEGA-based spectroscopic investigations that show mineralogic evidence of ancient (Noachian) aqueous activity elsewhere in the geologic record of Mars (e.g., Bibring et al., 2005; Poulet et al., 2005). Thus, the CRISM signature may be consistent with a geologic environment influenced by the interaction of magma, tectonism, and water at Claritas rise, as indicated by the stratigraphic, geomorphic, and paleotectonic information presented earlier. For example, a hydrothermal interpretation would be viable if the identified minerals indeed correspond to topographic highs, which are less likely to be mantled by dust than low areas, and the topographic highs are volcanic constructs. However, alternatives to a hydrothermal origin for the phyllosilicates may include: aqueous activity (e.g., Squyres et al., 2004b), deposition of volcanic ash with subsequent interaction of volatiles (e.g., McCollom and Hynek, 2005), impact cratering and subsequent weathering processes (e.g., Knauth et al., 2005), and erosion and migration of previously layered sulfate evaporites (e.g., Fan et al., 2008). Further work is necessary to identify and interpret the suite of rocks that form Claritas rise and other parts of the Thaumasia
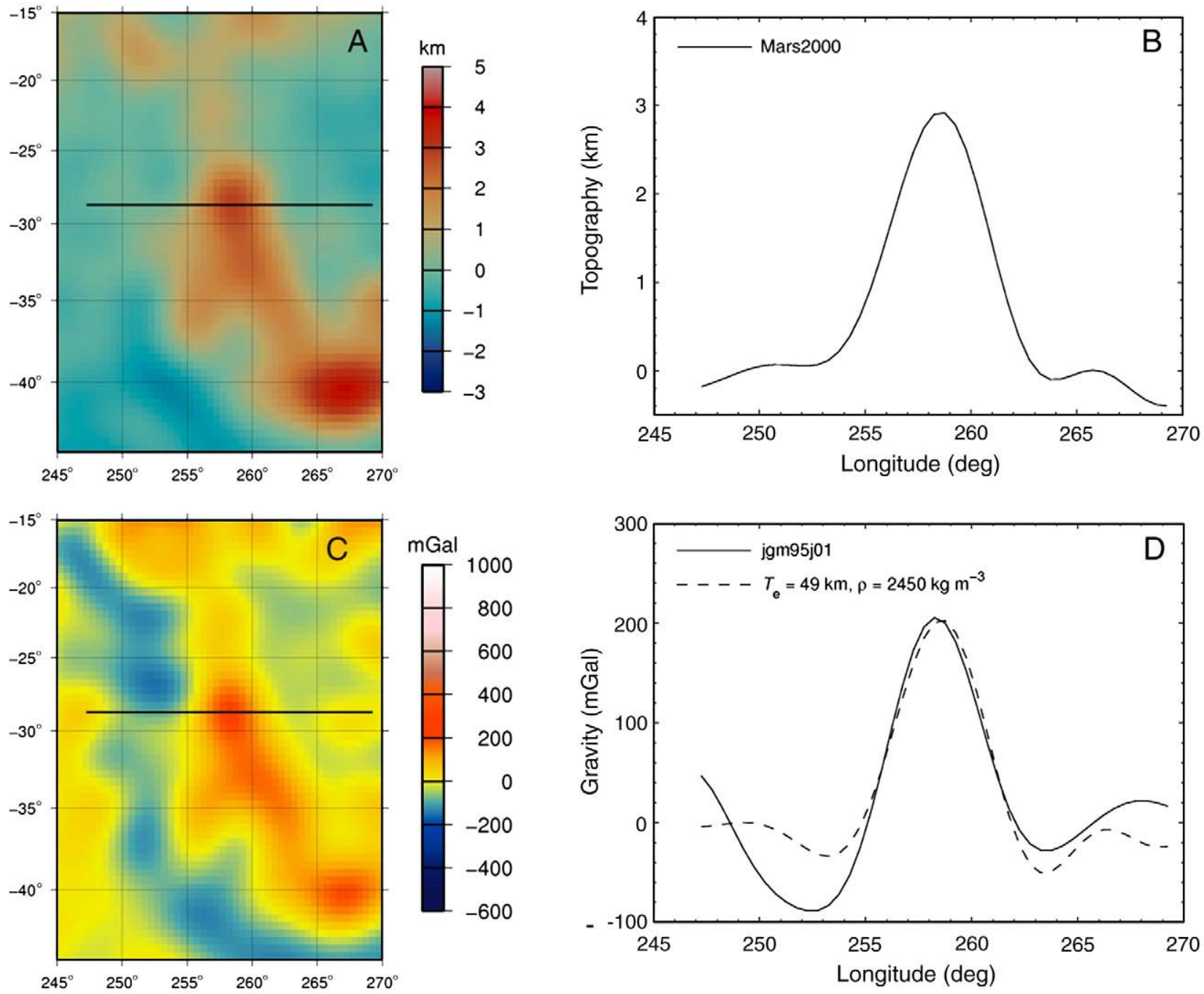

Fig. 14. Topography (A) and free-air gravity (C) and longitudinal profiles centered on Claritas rise (B) and (D) using harmonic degrees 5-75 of the spherical harmonic models Mars2000 (Smith et al., 2001) for topography and jgm95j01 (Konopliv et al., 2006) for gravity (solid lines) and the best-fit model profile (dashed line). Claritas rise represents a topographic and gravitational peak within the Thaumasia highlands. (For interpretation of the references to color in this figure legend, the reader is referred to the web version of this article.) 


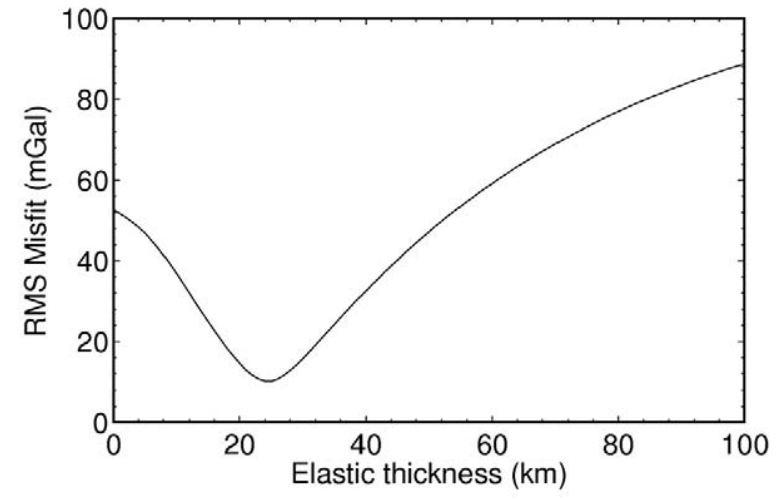

Fig. 15. RMS misfit as a function of elastic thickness with a constant crustal density of $2900 \mathrm{~kg} \mathrm{~m}^{-3}$ and mantle density of $3400 \mathrm{~kg} \mathrm{~m}^{-3}$.

highlands mountain range, as well as to determine whether the spectral signature may be indicative of magma-tectonism-water (hydrothermal) interactions.

\section{Geophysical investigation}

Claritas rise represents a topographic peak along Claritas Fossae standing $\sim 3 \mathrm{~km}$ above the surrounding terrain and is associated with a positive free-air gravity anomaly (Fig. 14). We have processed the spherical harmonic models of the topography, Mars2000 (Smith et al., 2001), and gravity, jgm95j01 (Konopliv et al., 2006) to assess the state of flexural compensation of the high-standing promontory and infer its density. We used harmonic degrees 5-75, thereby excluding degrees dominated by the hemisphere-scale Tharsis magmatic complex. From topography, the Bouguer gravity is determined by employing a gravity-topography transfer function derived from the formulation of Turcotte et al. (1981) for bending and membrane stresses in a thin-elastic shell. The gravity is related to the topography by:

$g_{\text {ilm }}=4 \pi G \rho_{\mathrm{c}}\left(\frac{l+1}{2 l+1}\right) h_{\text {ilm }}\left[1-\left(1-\frac{t_{\mathrm{cr}}}{R}\right)^{l+2} \alpha_{\mathrm{l}}\right]$

where $g_{\text {ilm }}$ and $h_{\text {ilm }}$ are harmonic coefficients for gravity and topography, respectively, for degree $l$, order $m$. The crustal density is $\rho_{\mathrm{c}}, G$ is the gravitational constant, and $t_{\mathrm{cr}}$ is the crustal thickness, assumed here to be $50 \mathrm{~km}$ (Zuber et al., 2000). The function $\alpha_{1}$ represents the degree of compensation for a given degree harmonic and is a function of the effective elastic thickness of the lithosphere, $T_{\mathrm{e}}$, and the elastic constants: Young's modulus, $10^{11} \mathrm{~Pa}$, and Poisson's ratio, 0.25 (Turcotte et al., 1981; Johnson et al., 2000).

Using a mantle density, $\rho_{\mathrm{m}}=3400 \mathrm{~kg} \mathrm{~m}^{-3}$, and an average crustal density for Mars, $\rho_{\mathrm{c}}=2900 \mathrm{~kg} \mathrm{~m}^{-3}$ (Zuber et al., 2000), we determine the RMS misfit between longitudes $255^{\circ}$ and $262^{\circ} \mathrm{E}$ for a longitudinal profile across the Claritas rise (Fig. 14). Minimizing the misfit between the observed gravity and the modeled Bouguer gravity while varying $T_{\mathrm{e}}$ from $0-100 \mathrm{~km}$ by $1 \mathrm{~km}$ increments yields a best fit of $T_{\mathrm{e}}=24 \mathrm{~km}$ (Fig. 15). Allowing the crustal density to also vary by increments of $50 \mathrm{~kg} \mathrm{~m}^{-3}$ results in a best-fit with smaller crustal density, $\rho_{\mathrm{c}}=$ $2450 \mathrm{~kg} \mathrm{~m}^{-3}$ and $T_{\mathrm{e}}=49 \mathrm{~km}$. The uncertainty in the gravity is no more than $10 \mathrm{mGals}$ (Wieczorek, 2007) giving a range of acceptable values for which the misfit is $<10 \mathrm{mGals}$ (Fig. 16). The distribution of acceptable models is bimodal, reflecting the trade off between load density and elastic thickness with a range of crustal densities, 2300 $2750 \mathrm{~kg} \mathrm{~m}^{-3}$, and elastic thicknesses, 31-61 km, around the minimum value, and a range of higher densities and lower elastic thickness of $3150-3250 \mathrm{~kg} \mathrm{~m}^{-3}$ and 9-14 km, respectively.

The high $\rho_{\mathrm{c}}$ and low $T_{\mathrm{e}}$ models have similar densities found for the large shield volcanoes of Tharsis, such as Olympus Mons, $3150 \mathrm{~kg} \mathrm{~m}^{-3}$, and the Tharsis Montes volcanoes, $3250-3300 \mathrm{~kg} \mathrm{~m}^{-3}$ (McGovern et al., 2004; Belleguic et al., 2005) and the small values for $T_{\mathrm{e}}$ are consistent with other Early Noachian terrains, including regions with magnetized crust such as Terra Cimmeria (McKenzie et al., 2002; McGovern et al., 2004; Grott et al., 2005; Kronberg et al., 2007). This would favor Claritas rise as a remanent of relatively intact dense igneous material formed on a weak, thin-elastic lithosphere early in Martian history when heat flow from the planet's interior was high. The low $\rho_{\mathrm{c}}$ and high $T_{\mathrm{e}}$ models however may indicate that Claritas has experienced significant impact modification. McGovern et al. (2004) found heavily cratered terrains such as northeast Arabia Terra and Noachis Terra to have surface densities of $2500 \mathrm{~kg} \mathrm{~m}^{-3}$ and $2800 \mathrm{~kg} \mathrm{~m}^{-3}$, respectively, and Nimmo (2002) found portions of the hemispheric crustal dichotomy boundary to have a surface density of $2500 \mathrm{~kg} \mathrm{~m}^{-3}$. Low surface densities have also been reported in the Tharsis region by McKenzie et al. (2002) and McGovern et al. (2004; these authors, however, prefer models with bottom loading and a surface density of $2900 \mathrm{~kg} \mathrm{~m}^{-3}$ ). The $T_{\mathrm{e}}$ values for the low density models, 31-61 km, are consistent with $T_{\mathrm{e}}$ values obtained for regions with surfaces that are Noachian/Hesperian to Hesperian in age (Zuber et al., 2000; McGovern et al., 2004).

The effective elastic thickness is related to the thermal structure of the lithosphere at the time when the topography was formed. This relation has been previously used in order to calculate surface heat flows for several regions of Mars (e.g., Solomon and Head, 1990; Zuber et al., 2000; McGovern et al., 2004; Grott et al., 2005; Ruiz et al., 2006; Kronberg et al., 2007; Ruiz et al., 2008). Moreover, the use of crustal heat sources in this kind of calculation increases the obtained heat flow values and potentially constrains crustal thickness estimates (Ruiz et al., 2006, 2008). Thus, we calculate surface heat flows from the best-fit effective elastic thicknesses and crustal densities obtained for Claritas rise (Fig. 15 ), as well as heat-producing elemental abundances deduced from Mars Odyssey Gamma Ray Spectrometer (GRS) data (Taylor et al., 2006).

The effective elastic thicknesses can be converted to heat flows following the equivalent strength envelope procedure described by McNutt (1984). This methodology is based on the condition that the bending moment of the mechanical lithosphere must be equal to the bending moment of the equivalent elastic layer of thickness $T_{\mathrm{e}}$,

$\frac{E K T_{\mathrm{e}}^{3}}{12\left(1-v^{2}\right)}=\int_{0}^{T_{\mathrm{m}}} \sigma(z)\left(z-z_{\mathrm{n}}\right) d z$

where $E$ is the Young's modulus, $K$ is the topography curvature, $v$ is the Poisson's ratio, $T_{\mathrm{m}}$ is the mechanical thickness of the lithosphere,

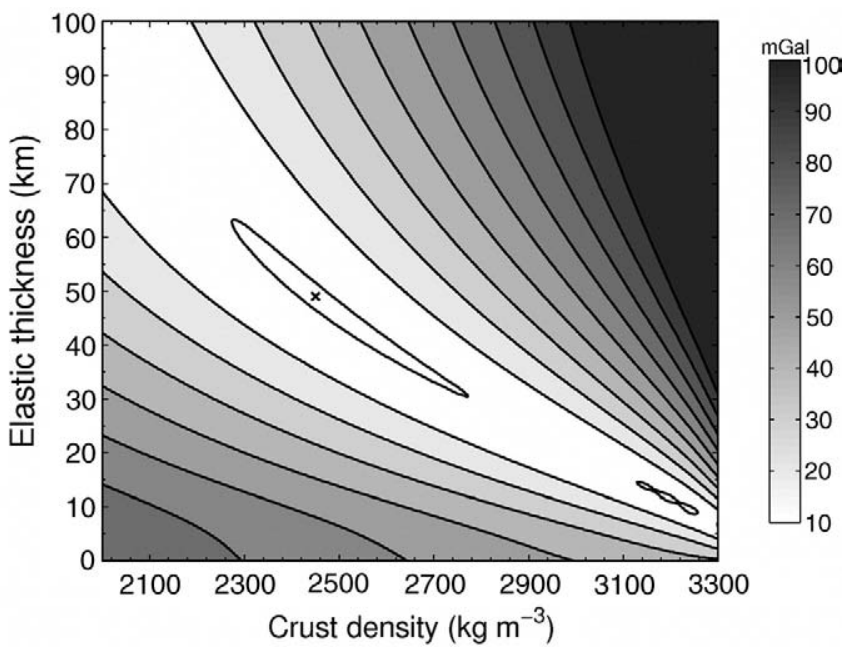

Fig. 16. Contours of misfit between observed and modeled gravity across the Claritas rise for varying crustal density and elastic thickness values. The contour intervals are $10 \mathrm{mGals}$ and range from $10-100 \mathrm{mGals}$. The best-fit value is denoted with ' $\times$ '. 


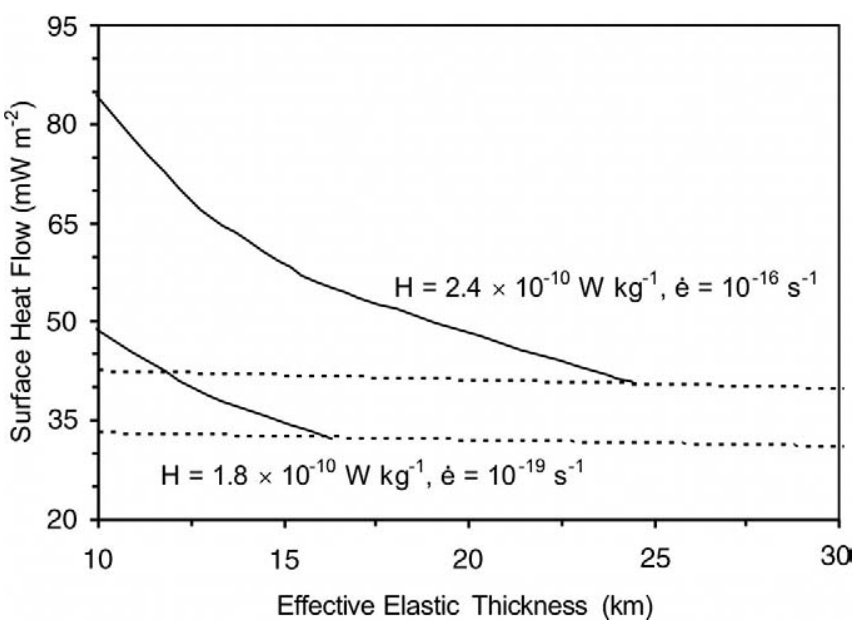

Fig. 17. Upper and lower limits (solid curves) for the surface heat flow shown as functions of the effective elastic thickness, strain rate (symbolized by $\dot{e}$ ), and heat production rate. Upper and lower limit are calculated, respectively, for topography curvatures of 2 and $7 \times 10^{-1}$. Under the dotted lines the heat flow reaching the mechanical lithosphere from below is negative, which is not permitted.

$\sigma(z)$ is the least of the brittle strength, the ductile strength, or the fiber stress at depth $z$ (which is in turn a function of the topography curvature), and $z_{\mathrm{n}}$ is the depth to the neutral stress plane. The link to heat flow comes from the dependence of the ductile strengths on the temperature profile. For details on the implementation of the methodology used here, please see Ruiz et al. (2008).

Temperature profiles in the crust are calculated by assuming heat sources homogeneously distributed. Hence, the temperature at a depth $z$ is given by:

$T_{\mathrm{z}}=T_{\mathrm{s}}+\frac{F z}{k}-\frac{H \rho_{\mathrm{c}} z^{2}}{2 k}$

where $T_{\mathrm{s}}$ is the surface temperature, $F$ is the surface heat flow, $k$ is the thermal conductivity of the crust, and $H$ is the heat production rate.

We use a surface temperature of $220 \mathrm{~K}$, the present-day mean surface temperature (Kieffer et al., 1977), and a thermal conductivity of the crust of $2 \mathrm{~W} \mathrm{~m}^{-1} \mathrm{~K}^{-1}$ (e.g., Grott et al., 2005). For the crustal heat production rate, we use potassium and thorium abundances of 3630 and $0.70 \mathrm{ppm}$, respectively, average values deduced from GRS data for the ancient southern highlands (Taylor et al., 2006). For uranium abundance, we use a Th/U ratio of 3.6 deduced from SNC meteorite geochemistry (McLennan, 2003). We calculate crustal heat production rates by using decay constants from Turcotte and Schubert (2002), and age bounds of 3.7 and $4.2 \mathrm{Ga}$ [which correspond, respectively, to the Noachian-Hesperian limit (Hartmann and Neukum, 2001), and to a reasonable upper limit for the Martian dynamo shutdown (Frey, 2006; Werner, 2008)], obtaining values between 1.8 and $2.4 \times 10^{-10} \mathrm{~W} \mathrm{~kg}^{-1}$.

In order to calculate the ductile strength of the Martian crust, we use the diabase flow law (Caristan, 1982). The use of a "standard" wet diabase for the Martian crust is consistent with extensive evidence for water-related geologic activity in early Mars (e.g., Fairén et al., 2003). For strain rates, we use values of $10^{-16} \mathrm{~s}^{-1}$ and $10^{-19} \mathrm{~s}^{-1}$, a range usually considered for Mars (e.g., McGovern et al., 2004; Ruiz et al., 2008).

The base of the mechanical lithosphere is defined as the depth at which the ductile strength of the crust reaches a low value of $10 \mathrm{MPa}$ (Ranalli, 1997); the mantle is assumed to not be contributing to the strength of the lithosphere, since the high crustal thickness in the region (Neumann et al., 2004) would imply a hot upper mantle in the Noachian. Finally, for the topography curvature, we use values of 2 and $7 \times 10^{-7} \mathrm{~m}^{-1}$, which limit a range including the majority of values published for Mars (e.g., Grott et al., 2005; Ruiz et al., 2006; Kronberg et al., 2007; Ruiz et al., 2008).

Fig. 17 shows upper and lower limits for the heat flow as a function of the effective elastic thickness. Solutions with negative sublithospheric heat flow are discarded. These non-valid solutions are obtained when the contribution to the surface heat flow due to radioactive heat production in the mechanical lithosphere (given by $H \rho_{\mathrm{c}} T_{\mathrm{m}}$ ) is higher than the surface heat flow. Thus, our results constrain the effective elastic thickness to be lower than $\sim 25 \mathrm{~km}$ (the case with $H=1.8 \times 10^{-10} \mathrm{~W} \mathrm{~kg}^{-1}$, strain rate $=10^{-16} \mathrm{~s}^{-1}$, and $K=2 \times 10^{-7} \mathrm{~m}^{-1}$, not shown, gives the maximum permitted $T_{\mathrm{e}}$ value, $27 \mathrm{~km}$ ), and the heat flow to be between 32 and $90 \mathrm{~mW} \mathrm{~m}^{-2}$.

A contribution to the surface heat flow is due to radioactive heating in the crust, whereas the remainder must reach the crust from the mantle. Thus, the heat flows shown in Fig. 17, combined with the condition of non-negative mantle heat flow, impose upper limits [given by $F /\left(H \rho_{\mathrm{c}}\right)$ ] on the crustal thickness. Fig. 18 shows these upper limits for strain rate $=10^{-16} \mathrm{~s}^{-1}$ and $K=2 \times 10^{-7} \mathrm{~m}^{-1}$, values maximizing both the surface heat flow and the maximum permitted crustal thickness. The so-obtained maximum crustal thicknesses shown in Fig. 18 can be compared with independent estimations for the thickness of the crust in the Claritas rise. After the crustal model of Neumann et al. (2004), the crust at the Claritas rise is $\sim 80 \mathrm{~km}$ thick. These authors assumed a mean thickness of $45 \mathrm{~km}$ for the Martian crust, whereas Wieczorek and Zuber (2004), by simultaneously considering several geophysical and geochemical considerations, constrained the average thickness of the crust to be between 38 and $62 \mathrm{~km}$, and Ruiz et al. (2008), through calculations of heat flows from the effective elastic thickness and faulting depth for the Amenthes region, found an average thickness of $\sim 45-65 \mathrm{~km}$ if the crustal density is taken as $2900 \mathrm{~kg} \mathrm{~m}^{-3}$. Thus, for the average crustal density value used in the model of Neumann et al. (2004), the crustal thickness beneath Claritas rise would be between $~ 75$ and $\sim 100 \mathrm{~km}$, which further constrain the effective elastic thickness to be lower than $23 \mathrm{~km}$.

Our heat flow calculations, therefore, favor the high $\rho_{\mathrm{c}}$ and low $T_{\mathrm{e}}$ models deduced from our analysis of the state of flexural compensation of the topography. Hence, the results are consistent with the

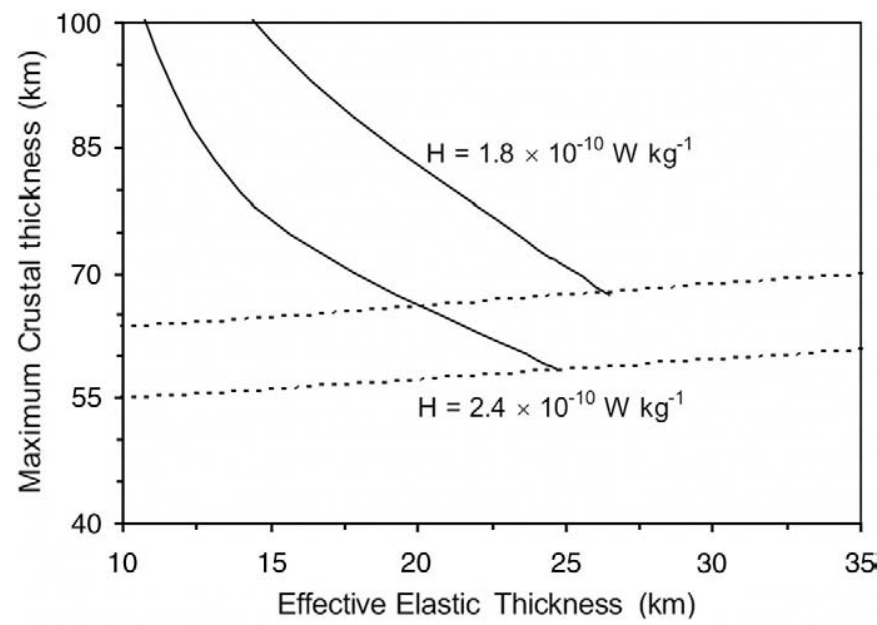

Fig. 18. Maximum permitted crustal thicknesses (solid curves) obtained from surface heat flows and the condition of non-negative mantle heat flow, as a function of the effective elastic thickness and heat production rate. Calculations have been performed by $\dot{e}=10^{-16} \mathrm{~s}^{-1}$ and $K=2 \times 10^{-7} \mathrm{~m}^{-1}$. Under the dotted curves the heat flow reaching the mechanical lithosphere from below is negative, which is not permitted. 
interpretation of Claritas rise being a remnant of dense igneous material formed above an early and hot lithosphere.

\section{Discussion}

Mars has had a dynamic geologic history, influenced by both exogenic (including impact events; Segura et al., 2002) and endogenic processes such as illustrated by the evolution of the Tharsis magmatic complex/superplume (Baker et al., 2007; Dohm et al., 2007). Tharsis is composed of giant shield volcanoes, igneous plateaus, magmaticdriven centers of tectonic activity, fault and rift systems, vast canyon system, and lava flow fields. The paleotectonic record of the Tharsis and surrounding regions includes plume-driven activity, ranging from a mantle plume (e.g., Mège and Masson, 1996) to a superplume (Maruyama, 1994; Baker et al., 2001; Dohm et al., 2001b; Baker et al., 2007; Dohm et al., 2007), dike emplacement (McKenzie and Nimmo, 1999; Wilson and Head, 2002), and crustal/lithospheric flexure related to its growth (e.g., Golombek, 1989; Banerdt et al., 1992). The record includes radial faults and circumferential systems of wrinkle ridges and fold belts (Schultz and Tanaka, 1994) centered about local and regional centers of magmatic-driven activity related to the growth of Tharsis (Anderson et al., 2001). One such center is Claritas rise, a highly-deformed promontory with more than 850 fault segments pointing back to it. This promontory is marked by tectonic structures that may indicate contractional deformation related to orogenic activity (Anguita et al., 2006).

Stratigraphic (e.g., Scott and Tanaka, 1986), paleotectonic (e.g., Anderson et al., 2001), spectroscopic, and geophysical information collectively point to the Claritas rise as a distinct feature that occurs along a major zone of crustal/lithospheric weakness, which includes Claritas Fossae and a north-northwest alignment of major features, including Claritas rise, Syria Planum, Ascraeus Mons, Ceraunius rise, and Alba Patera (Fig. 8). As a distinct feature, did this prominent center of tectonism form prior to Tharsis or incipient Tharsis development, as one of the ancient components of the superplume? Was this feature, therefore, the result of plume-related activity, and thus a potential site of ancient hydrothermal activity? Certainly the Claritas rise is an ancient feature, but how ancient? It likely formed when the magnetosphere was in operation, but this is difficult to determine for sure even though a magnetic anomaly appears to be spatially associated with it This uncertainty is due to the major resurfacing related to the evolution of Tharsis to the north, northeast, and east, which has occurred since the Noachian Period, likely erasing any signature of Tharsis' possible magnetic past (at least at current resolution). Arguably, Tharsis evolved during the stagnant-lid phase of Mars' evolution, following the shut down of the dynamo and possible plate tectonism (Baker et al., 2007).

The topographic and paleotectonic signatures, as well as results from investigation of the geophysical data, may be most readily explained by intrusive activity such as the manifestation of a plume. Investigation of the CRISM data reveals Claritas rise-forming materials to be at least partly composed of Fe/Mg-rich hydrated phyllosilicates. On Earth, hydrated iron/magnesium phyllosilicates are often the secondary product of weathering and aqueous activity, which may include hydrothermal activity. Though consistent with a possible intrusive history, alone it does not provide a definitive answer as to whether the geologic history of Claritas rise is dominated by igneous (plume) activity. Collectively, however, the various lines of evidence make this a distinct possibility. As an extremely ancient center of intrusive (plume)-related activity, which includes uplift, tectonism, and possible hydrothermal activity possibly during the period in which the magnetosphere was active, Claritas rise should be further targeted by orbiting Mars Odyssey, Mars Express, and Mars Reconnaissance Orbiter spacecrafts. In addition, as a site of possible ancient hydrothermal activity, and thus elevated life potential (Schulze-Makuch et al., 2007), it should be considered a prime target for future lifedetection missions.

\section{Summary and implications}

Significant characteristics of Claritas rise include:

(1) A well-defined, highly-deformed promontory located to the south of Syria Planum along a crustal/lithospheric zone of weakness, interpreted to be basement complex among other rock types (e.g., Scott and Tanaka, 1986).

(2) A center of tectonism, which includes the greatest percentage of faults preserved in Noachian materials (Anderson et al., 2001).

(3) A distinct spectroscopic signature, including $\mathrm{Fe} / \mathrm{Mg}$-rich hydrated phyllosilicates, when compared to the well-defined lava flows of Syria and Solis Planae.

(4) A possible magnetic signature, though this is difficult to determine due to Tharsis-related resurfacing to the north, northeast, and east.

(5) Geophysical results consistent with dense igneous material formed on a weak, thin-elastic lithosphere early in Martian history when heat flow from the planet's interior was much higher.

Based on these characteristics, Claritas rise is interpreted to result from intrusive (plume)-driven activity, which includes uplift and associated tectonism, as well as possible igneous and hydrothermal activity (Anderson et al., 2001; Dohm et al., 2001a,b). Since Tharsis has been reported to lack magnetic signatures, Claritas rise may mark either preTharsis activity or incipient Tharsis development, as some of the older parts of the giant magmatic complex could have been highly resurfaced, destroying any remanent magnetism.

While the planetary community currently has unprecedented access to high quality data, there continue to be many questions which are exceedingly difficult to address through orbital-based investigations. The geology of complex regions, such as Claritas rise, can only be interpreted from orbital-based data at present (as the terrain is considered too rugged to safely land a spacecraft with current technology). There is a fundamental lack of "ground truth"-the lifeblood of field geologists-for the ancient mountain ranges such as the Thaumasia highlands. Even with such formidable instruments as TES, CRISM, and the GRS, the compositions of the range-forming parent rocks are currently unknown. This is largely due to their age and the time available for extensive modification (even considering the lower erosional rates as compared to Earth), which includes obscuration by mantling (e.g., dust), secondary weathering rinds, and flows (e.g., alluvial fans reminiscent of the Atacama Desert, Chile, which has been often used as a terrestrial analogue for the Martian surface (Chong et al., 1999; Cabrol et al., 2007)). However, further data acquisition and investigation is necessary, as such may yield significant clues to this complex puzzle.

A potential solution to these problems is, of course, direct sampling of the surface by landers and rovers, as well as an eventual sample return mission. In order to perform in situ reconnaissance of these extremely rugged terrains, a new paradigm in planetary exploration is required, which includes tier-scalable exploration (e.g., see Fink et al., 2005). The potential scientific payoff for such missions is huge. For instance, if the mountains of the Thaumasia Highlands were calcalkaline in composition, this would have major implications about the early history and formation of the planet, suggesting that ancient Mars may have been more Earth-like in its evolution than is predominantly interpreted (e.g., plate tectonism and the formation of a tertiary crust).

\section{Acknowledgements}

The authors are indebted to two technical reviewers, Daniel Mège and an anonymous reviewer, whose efforts have resulted in a 
significantly improved manuscript. We are also appreciative of helpful inputs by $\mathrm{H}$. Jay Melosh, as well as machine learning-related information contributed by Rebecca Castano and Brad Dalton (Section 3.1). James Dohm was supported by the NASA Mars Data Analysis Program, Javier Ruiz by a contract I3P with the CSIC, co-financed from the European Social Fund, Jean-Pierre Williams by the California Institute of Technology through the O. K. Earl Postdoctoral Fellowship and the National Science Foundations Astronomy and Astrophysics Research Grants program (AST-0709151), Patrick McGuire by a Robert M. Walker senior research fellowship from the McDonnell Center for the Space Sciences, and by NASA funds through the Applied Physics Laboratory, under subcontract from the Jet Propulsion Laboratory (JPL Contract \#1277793).

\section{References}

Acuña, M.H., 1999. Global distribution of crustal magnetization discovered by the Mars Global Surveyor MAG/ER experiment. Science 284, 790-793.

Anderson, R.C., Dohm, J.M., Golombek, M.P., Haldemann, A., Franklin, B.J., Tanaka, K.L., Lias, J., Peer, B., 2001. Significant centers of tectonic activity through time for the western hemisphere of Mars. J. Geophys. Res. 106, 20,563-20,585.

Anderson, R.C., Dohm, J.M., Haldemann, A.F.C., Hare, T.M., Baker, V.R., 2004. Tectonic histories between Alba Patera and Syria Planum, Mars. Icarus 171, 31-38.

Anguita, F., Fernández, C., Cordero, G., Carrasquilla, S., Anguita, J., Núñez, A., Rodriguez, S., Garcia, J., 2006. Evidences for a Noachian-Hesperian orogeny in Mars. Icarus 185, 331-357.

Arkani-Hamed, J., 2003. Thermoremanent magnetization of the Martian lithosphere. J. Geophys. Res. 108. doi:10.1029/2003JE002049.

Baker, V.R., Maruyama, S., Dohm, J.M., 2001. Tharsis superplume (3): implications on the role of water, environmental change and life. Geol. Soc. America Abstracts with Programs, vol. 33(7), p. A432.

Baker, V.R., Maruyama, S., Dohm, J.M., 2007. Tharsis superplume and the geological evolution of early Mars. In: Yuen, D.A., Maruyama, S., Karato, S.-I., Windley, B.F. (Eds.), Superplumes: Beyond Plate Tectonics. Springer, pp. 507-523.

Bandfield, J.L., Smith, M.D., 2003. Multiple emission angle surface-atmosphere separations of Thermal Emission Spectrometer data. Icarus 161, 47-65.

Bandfield, J.L., Hamilton, V.E., Christensen, P.R., 2000. A global view of Martian surface compositions from MGS-TES. Science 287, 1626.

Banerdt, W.B., Golombek, M.P., Tanaka, K.L., 1992. Stress and tectonics on Mars, chapter 8. In: Kieffer, H.H., Jakosky, B.M., Snyder, C.W., Matthews, M.S. (Eds.), MARS. University of Arizona Press, Tucson, pp. 249-297. 1498.

Belleguic, V., Lognonné, P., Wieczorek, M., 2005. Constraints on the Martian lithosphere from gravity and topography data. J. Geophys. Res. 110, E11005. doi:10.1029/ 2005JE00243.

Bibring, J.-P., Langevin, Y., Gendrin, A., Gondet, B., Poulet, F., Berthé, M., Soufflot, A., Arvidson, R., Mangold, N., Mustard, J., Drossart, P., the OMEGA team, 2005. Mars surface diversity as revealed by the OMEGA/Mars express observations. Science $307,1576$.

Bishop, J.L., Murchie, S.L., Tornabene, L.L., Pelkey, S.M., Gulick, V.C., Ehlmann, B.L., Mustard, J.F., Brown, A.J., MRO CRISM Team, 2007. Characterization of Phyllosilicates in Libya Montes and the Southern Isidis Planitia Region Using CRISM and HiRISE images. 7th Internat. Conf. on Mars, Pasadena, Extended Abstract \#3294.

Bishop, J.L., McKeown, N.K., Noe Dobrea, E.Z., Ehlmann, B.L., Michalski, J.R., Milliken, R.E., Poulet, F., Mustard, J.F., Swayze, G.A., Murchie, S.L., Bibring J.-P., and the CRISM Team, 2008a. Phyllosilicate diversity and past aqueous activity observed by MRO/ CRISM in Mawrth Vallis: identification of nontronite, montmorillonite, kaolinite, and hydrated silica. LPSCXXXIX, League City, Texas, extended abstract \#2124.

Bishop, J.L., Dobrea, Noe, E.Z., McKeown, N.K., Parente, M., Ehlmann, B.L., Michalski, J.R., Milliken, R.E., Poulet, F., Swayze, G.A., Mustard, J.F., Murchie, S.L., and Bibring, J.-P., 2008b. Phyllosilicate Diversity and Past Aqueous Activity Revealed by MRO/CRISM at Mawrth Vallis, Mars. (submitted to Science)

Cabrol, N.A., et al., 2007. Life in the Atacama: searching for life with rovers (science overview). J. Geophys. Res. 112, G04S02. doi:10.1029/2006JG000298.

Caristan, Y., 1982. The transitions from high temperature creep to fracture in Maryland diabase. J. Geophys. Res. 87, 6781-6790.

Chong Diaz, G., Mendoza, M., Garcia-Veigas, J., Pueyo, J.J., Turner, P., 1999. Evolution and geochemical signatures in a Neogene forearc evaporitic basin: the Salar Grande (Central Andes of Chile). Palaeogeog. Palaeoclim. Palaeoecol. 151, 39-54.

Christensen, P.R., et al., 2000. Identification of a basaltic component on the Martian surface from Thermal Emission Spectrometer data. J. Geophys. Res 105, 9609-9621.

Christensen, P.R., et al., 2001a. The Mars Global Surveyor Thermal Emission Spectrometer experiment: investigation description and surface science results. J. Geophys. Res. 106, 23,823-23,871 2001a.

Christensen, P.R., Morris, R.V., Lane, M.D., Bandfield, J.L., Malin, M.C., 2001b. Global mapping of Martian hematite mineral deposits: remnants of water-driven processes on early Mars. J. Geophys. Res. 106, 23,873-23,886.

Christensen, P.R., et al., 2005. The igneous diversity of Mars: evidence for magmatic evolution analogous to Earth. Lunar Planet. Sci. Conf. [CD-ROM], XXXVI, abstract 1273.
Connerney, J.E.P., Acuña, M.H., Wasilewski, P.J., Kletetschka, G., Ness, N.F., Rème, H., Lin, R.P., Mitchell, D.L., 1999. The global magnetic field of Mars and implications for crustal evolution. Science 284, 790-793.

Connerney, J.E.P., Acuna, M.H., Wasilewski, P., Kletetschka, G., Ness, N.F., Reme, H., Lin, R.P., Mitchell, D., 2001. The global magnetic field of Mars and implications for crustal evolution. Geophys. Res. Lett. 28, 4015-4018.

Connerney, J.E.P., et al., 2005. Tectonic implications of Mars crustal magnetism. Science $102,14970-14975$

Dohm, J.M., Tanaka, K.L., Hare, T.M., 1997. Tharsis-centered and other fault activity in the Thaumasia region. Lunar Planet. Sci. Conf., XXVIII, 303-304.

Dohm, J.M., Tanaka, K.L., 1999. Geology of the Thaumasia region, Mars: plateau development, valley origins, and magmatic evolution. Planetary and Space Science 47, 411-431.

Dohm, J.M., Ferris, J.C., Baker, V.R., Anderson, R.C., Hare, T.M., Strom, R.G., Barlow, N.G., Tanaka, K.L., Klemaszewski, J.E., Scott, D.H., 2001a. Ancient drainage basin of the Tharsis region, Mars: potential source for outflow channel systems and putative oceans or paleolakes. J. Geophys. Res. 106, 32 943-32 958.

Dohm, J.M., Tanaka, K.L., Hare, T.M., 2001b. Geologic map of the Thaumasia region of Mars. US Geol. Survey Map I-2650.

Dohm, J.M., Maruyama, Shigenori, Baker, V.R., Anderson, R.C., Ferris, J.C., 2001c. Earthlike evolution of the Tharsis Magmatic Complex: traits of a Terrestrial Superplume (2). Geol. Soc. America Abstracts with Programs, vol. 33(7), p. A309.

Dohm, J.M., Maruyama, S., Baker, V.R., Anderson, R.C., Ferris, J.C., Hare, T.M., 2002. Plate tectonism on early Mars: diverse geological and geophysical evidence. Lunar Planet. Sci. Conf., XXXIII, \#1639 (abstract) (CD-ROM)

Dohm, J.M., et al., 2005. Mars geological province designations for the interpretation of GRS data. Lunar Planet. Sci. Conf. XXXVI, \#1567 (abstract) [CD-ROM].

Dohm, J.M., Baker, V.R., Maruyama, S., Anderson, R.C., 2007. Traits and evolution of the Tharsis superplume, Mars. In: Yuen, D.A., Maruyama, S., Karato, S.-I., Windley, B.F. (Eds.), Superplumes: Beyond Plate Tectonics. Springer, pp. 523-537.

Dohm, J.M., et al., 2009. New evidence for a magmatic influence on the origin of Valles Marineris. J. Volcanol. Geotherm. Res. 185, 12-27(this issue)

Ehlmann, B.L., Mustard, J.F., Murchie, S.L., 2009a. Detection of serpentine on Mars by MRO-CRISM and possible relationship with olivine and magnesium carbonate in Nili Fossae. submitted to Lunar Planet. Sci., XL (abstract)

Ehlmann, B., Mustard, J.F., Swayze, G.A., Clark, R.N., Bishop, J.L., Poulet, F., Des Marais, D., Roach, L.H., Wray, J.J., Barnouin-Jha, O.S., Milliken, R.E., Murchie, S.L., 2009b. Identification of hydrated silicate minerals on Mars using MRO-CRISM: geologic context near Nili Fossae and implications for aqueous alteration. submitted to J. Geophys. Res.

Eugster, O., Herzog, G.F., Marti, K., Caffee, M.W., 2006. Irradiation records, cosmic-ray exposure ages, and transfer times of meteorites. In: Lauretta, Dante S., McSween, Harry Y. (Eds.), Meteorites and the Early System II. The University of Arizona Press. $942 \mathrm{pp}$.

Fairén, A.G., Ruiz, J., Anguita, F., 2002. An origin for the linear magnetic anomalies on Mars through accretion of terranes: implications for dynamo timing. Icarus 160, 220-223.

Fairén, A.G., Dohm, J.M., Baker, V.R., de Pablo, M.A., Ruiz, J., Ferris, J.C., Anderson, R.C. 2003. Episodic flood inundations of the northern plains of Mars. Icarus 165, 53-67.

Fan, C., Schulze-Makuch, D., Fairén, A.G., Wolff, J.A., 2008. A new hypothesis for the origin and redistribution of sulfates in the equatorial region of western Mars. Geophys. Res. Lett. 35, L06201. doi:10.1029/2007GL033079.

Frey, H.V., 2006. Impact constraints on, and a chronology for, major events in early Mars history. J. Geophys. Res. 111, E08S91. doi:10.1029/2005JE002449.

Fink, W., Dohm, J.M., Tarbell, M.A., Hare, T.M., Baker, V.R., 2005. Next-generation robotic planetary reconnaissance missions: a paradigm shift. Planet. Space Sci. 53, 1419-1426.

Gendrin, A., Mangold, N., Bibring, J.P., Langevin, Y., Gondet, B., Poulet, F., Bonello, G. Quantin, C., Mustard, J., Arvidson, R., LeMouelic, S., 2005. Sulfates in Martian layered terrains: the OMEGA/Mars express view. Science 307. doi:10.1126/science.1109087.

Golombek, M.P., 1989. Geometry of stresses around Tharsis on Mars. Lunar Planet. Sci. 345-346 XX, (abstract).

Grott, M., Hauber, E., Werner, S.C., Kronberg, P., Neukum, G., 2005. High heat flux on ancient Mars: evidence from rift flank uplift at Coracis Fossae. Geophys. Res. Lett. 32, L21201. doi:10.1029/2005GL023894.

Grott, M., Hauber, E., Werner, S.C., Krongberg, P., Nuekum, G., 2007. Mechanical modeling of thrust faults in the Thaumasia region, Mars, and implications for the Noachian heat flux. Icarus 186, 517-526.

Halliday, A.N., Wanke, H., Birck, J.-L., Clayton, R.N., 2001. The accretion, composition and early differentiation of Mars. Space Sci. Rev. 96, 197-230.

Hartmann, W.K., Neukum, G., 2001. Cratering chronology and the evolution of Mars. Space Sci. Rev. 96, 165-194.

Johnson, C.L., Solomon, S.C., Head, J.W., Smith, D.E., Zuber, M.T., 2000. Lithospheric loading by the northern polar cap on Mars. Icarus 144, 313-328.

Kieffer, H.H., Martin, T.Z., Peterfreund, A.R., Jakosky, B.M., Miner, E.D., Palluconi, F.D., 1977. Thermal and albedo mapping of Mars during the Viking primary mission. J. Geophys. Res. 82, 4249-4291

Knauth, L.P., Burt, D.M., Wohletz, K.H., 2005. Impact origin of sediments at the Opportunity landing site on Mars. Nature 438, 1123-1128.

Konopliv, A.S., Yoder, C.F., Standish, E.M., Yuan, D.-N., Sjogren, W.L., 2006. A global solution for the Mars static and seasonal gravity, Mars orientation, Phobos and Deimos masses, and Mars ephemeris. Icarus 182, 23-50.

Kronberg P. Hauber, E., Grott, M., Werner, S.C., Schäfer, T., Gwinner, K., Giese, B., Masson, P., Neukum, G., 2007. Acheron Fossae, Mars: tectonic rifting, volcanism, and implications for lithospheric thickness. J. Geophys. Res. 112, E04005. doi:10.1029/ 2002JE001854.

Langevin, Y., Poulet, F., Bibring, J.-P., Gondet, B., 2005. Sulfates in the north polar region of Mars detected by OMEGA/Mars Express. Science 307, 1584-1586. 
Malin, M.C., Edgett, K.S., 2000. Sedimentary rocks on early Mars. Science 290, 1927-1937.

Maruyama, S., 1994. Plume tectonics. J. Geol. Soc. Japan 100, 24-49.

McCollom, T.M., Hynek, B.M., 2005. A volcanic environment for bedrock diagenesis at Meridiani Planum on Mars. Nature 438, 1129-1131.

McGovern, P.J., Solomon, S.C., Smith, D.E., Zuber, M.T., Simons, M., Wieczorek, M.A., Phillips, R.J., Neumann, G.A., Aharonson, O., Head, J.W., 2004. Correction to "localized gravity/topography admittance and correlation spectra on Mars: implications for regional and global evolution. J. Geophys. Res. 109, E07007. doi:10.1029/2004JE002286.

McKenzie, D., Nimmo, F., 1999. The generation of Martian floods by the melting of ground ice above dykes. Nature 397, 231-233.

McKenzie, D., Barnett, D.N., Yuan, D.-N., 2002. The relationship between gravity and topography, Earth Planet. Sci. Lett., 195, 1-16.

McKeown, N.K., Bishop, J.L., Noe Dobrea, E.Z., Ehlmann, B.L., Michalski, J.R., Mustard, J.F. Murchie, S.L., Silver, E., Bibring, J.-P., the CRISM Team, 2008. The distribution of phyllosilicates in Mawrth Vallis as seen by CRISM. LPSCXXXIX, League City, Texas, Extended Abstract \#1400.

McLennan, S.M., 2003. Large-ion lithophile element fractionation during the early differentiation of Mars and the composition of the Martian primitive mantle. Meteor. Planet. Sci 38, 895-904

McNutt, M.K., 1984. Lithospheric flexure and thermal anomalies. J. Geophys. Res. 89 $11,180-11,194$

Mège, D., Masson, P., 1996. A plume tectonics model for the Tharsis province. Mars. Planet. Space Sci 44, 1499-1546.

Mège, D., Cook, A.C., Garel, E., Lagabrielle, Y., Cormier, M.-H., 2003. Volcanic rifting at Martian grabens. J. Geophys. Res. 108, 5044. doi:10.1029/2002JE001852.

Merceron, T., Vieillard, P., Fouillac, Anne-Marie, Meunier, A., 1992. Hydrothermal alterations in the Echassieres granitic cupola (Massif central, France). Contrib. Mineral. Petrol. 112, 279-292.

Milliken, R.E., Grotzinger, J.P., Murchie, S., Grant, J.A., the CRISM Team, 2008a. Evidence for hydrated phyllosilicates in Holden Crater, Mars using Hyperspectral CRISM data. LPSCXXXIX, League City, Texas, Extended Abstract \#1913.

Milliken, R.E. Swayze, G.A. Arvidson, R.E, Bishop, J.L. Clark, R.N., Ehlmann, B.L, Green, R.O., Grotzinger, J., Morris, R.V., Murchie, S.L., Mustard, J.F., Weitz, C.M., CRISM Science Team, 2008b. Opaline silica in young deposits on Mars. Geology 36 (11), 847-850.

Murchie, S., Milliken, R., Roach, L., Bibring, J.-P., Mustard, J., Pelkey, S., Seelos, F., Bishop, J., Grotzinger, J, McEwen, A the CRISM Science Team, 2007a. CRISM mapping of layered deposits in Western Candor Chasma. Seventh International Conference on Mars, Extended Abstract \#3238.

Murchie, S., Arvidson, R., Bedini, P., Beisser, K., Bibring, J.-P., Bishop, J., Boldt, J., Cavender P. Choo, T. Clancy, RT Darlington, E.H. Des Marais, D., Espiritu, R, Fort, D. Green, R., Guinness, E., Hayes, J., Hash, C., Heffernan, K., Hemmler, J., Heyler, G., Humm, D., Hutcheson, J., Izenberg, N., Lee, R., Lees, J., Lohr, D., Malaret, E., Martin, T., McGovern, J.A., McGuire, P., Morris, R., Mustard, J., Pelkey, S., Rhodes, E., Robinson, M., Roush, T. Schaefer, E., Seagrave, G., Seelos, F., Silverglate, P., Slavney, S., Smith, M., Shyong, W.-J., Strohbehn, K., Taylor, H., Thompson, P., Tossman, B., Wirzburger, M., Wolff, M., 2007b. CRISM (Compact Reconnaissance Imaging Spectrometer for Mars) on MRO (Mars Reconnaissance Orbiter. J. Geophys. Res 112, 1-57.

Murchie, S.L., Roach, L.H., Seelos, F.P., Milliken, R.E., Mustard, J.F., Arvidson, R.E. Wiseman, S., Lichtenberg, K., Andrews-Hanna, J., Bibring, J.-P., Bishop, J.L., Parente, M., Morris, R.V., in press. Compositional Evidence for the Origin of Layered Deposits in Valles Marineris, Mars. J. Geophys. Res.

Mustard, J.F., Poulet, F., Head, J.W., Mangold, N., Bibring, J.-P., Pelkey, S.M., Fassett, C.I., Langevin, Y., Neukum, G., 2007. Mineralogy of the Nili Fossae region with OMEGA/ Mars express data: 1. ancient impact melt in the Isidis Basin and implications for the transition from the Noachian to Hesperian. J. Geophys. Res. 112, E08S03 1-14

Mustard, J.F., Murchie, S.L., Pelkey, S.M., Ehlmann, B.L., Milliken, R.E., Grant, J.A., Bibring, J.-P., Poulet, F., Bishop, J., Dobrea, E., Noe, Roach, L., Seelos, F., Arvidson, R.E. Wiseman, S., Green, R., Hash, C., Humm, D., Malaret, E., McGovern, J.A., Seelos, K., Clancy, T., Clark, R., Des Marais, D. Izenberg N., Knudson, A. Langevin, Y., Martin, T., McGuire, P., Morris, R., Robinson, M., Roush, T., Smith, M., Swayze, G., Taylor, H., Titus, T., Wolff, M., 2008. Hydrated silicate minerals on Mars observed by the CRISM instrument on MRO. Nature 454, 305-309.

Neumann, G.A., Zuber, M.T., Wieczorek, M.A., McGovern, P.J., Lemoine, F.G., Smith, D.E. 2004. The crustal structure of Mars from gravity and topography. J. Geophys. Res. 109, E08002. doi:10.1029/2004JE002262.
Nimmo, F., 2002. Admittance estimates of mean crustal thickness and density at the Martian hemispheric dichotomy. J. Geophys. Res. 107, E11, 5117. doi:10.1029/ 2000JE001488

Nimmo, F., Tanaka, K.L., 2005. Early crustal evolution of Mars. Annu. Rev. Earth Planet. Sci 33, 133-161.

Pelkey, S.M., Mustard, J.F., Murchie, S., Clancy, R.T., Wolff, M., Smith, M., Milliken, R. Bibring, J.-P., Gendrin, A., Poulet, F., Langevin, Y., Gondet, B., 2007. CRISM multispectral summary products: parameterizing mineral diversity on Mars from reflectance. J. Geophys. Res 112, 1-18.

Poulet, F. Bibring J.-P. Mustard, J.F., Gendrin, A., Mangold, N. Langevin, Y, Arvidson, R.E. Gondet, B., Gomez, C., the OMEGA Team, 2005. Phyllosilicates on Mars and implications for early Martian climate. Nature 438, 623-627.

Ranalli, G., 1997. Rheology of the lithosphere in space and time. Geol. Soc. Spec. Pub. 121, 19-37.

Rieder, R., et al., 2004. Chemistry of rocks and soils at Meridiani Planum from the alpha particle X-ray spectrometer. Science 306, 1746-1749.

Ruff, S.W., 2003. Basaltic andesite or weathered basalt: a new assessment. 6th Intern. Conf. on Mars (Abstract).

Ruiz, J., McGovern, P.J., Tejero, R., 2006. The early thermal and magnetic state of the cratered highlands of Mars. Earth Planet. Sci. Lett 241, 2-10.

Ruiz, J., Fernández, C., Gomez-Ortiz, D., Dohm, J.M., López, V., Tejero, R., 2008. Ancient heat flow, crustal thickness, and lithospheric mantle rheology in the Amenthes region, Mars. Earth Planet. Sci. Lett. doi:10.1016/j.epsl.2008.02.015.

Schultz, R.A., Tanaka, K.L., 1994. Lithospheric buckling and thrust structures on Mars: the Coprates rise and south Tharsis ridge belt. J. Geophys. Res. 99, 8371-8385.

Schulze-Makuch, D., Dohm, J.M., Fan, C., Fairén, A.G., Rodriguez, J.A.P., Baker, V.R., Fink, W., 2007. Exploration of hydrothermal targets on Mars. Icarus 189, 308-324.

Scott, D.H., Tanaka, K.L., 1986. Geologic map of the western equatorial region of Mars. USGS Misc. Inv. Ser. Map I-1802-A (1:15,000,000).

Segura, T.L., Toon, O.B., Colaprete, A., Zahnle, K., 2002. Environmental effects of large impacts on Mars. Science 298, 1977-1980.

Sleep, N.H., 1994. Martian plate tectonics. J. Geophys. Res. 99, 5,639-5,655.

Smith, M.D., Bandfield, J.L., Christensen, P.R., 2000. Separation of atmospheric and surface spectral features in Mars Global Surveyor Thermal Emission Spectrometer (TES) spectra. J. Geophys. Res. 104, 9589-9608.

Smith, D.E., Zuber, M.T., Frey, H.V., Garvin, J.B., Head, J.W., Muhleman, D.O., Pettengill, G.H., Phillips, R.J., Solomon, S.C., Zwally, H.J., Banerdt, W.B., Duxbury, T.C., Golombek, M.P., Lemoine, F.G., Neumann, G.A., Rowlands, D.D., Aharonson, O., Ford, P.G., Ivanov, A.B., Johnson, C.L., McGovern, P.J., Abshire, J.B., Afzal, R.S., Sun, X., 2001. Mars Orbiter Laser Altimeter: experiment summary after the first year of global mapping of Mars. J. Geophys. Res. 106, 23,689-23,722.

Solomon, S.C., Head, J.W., 1990. Heterogeneities in the thickness of the elastic lithosphere of Mars: constraints on heat flow and internal dynamics. J. Geophys. Res. 95, 11,073-11,083.

Squyres, S.W., et al., 2004a. The Spirit Rover's Athena Science Investigation at Gusev Crater. Mars. Science 305, 794-799.

Squyres, S.W., et al., 2004b. In situ evidence for an ancient aqueous environment at Meridiani Planum, Mars. Science 306, 1709-1714.

Taylor, G.J., et al., 2006. Bulk composition and early differentiation of Mars. J. Geophys. Res. 111, E03S10. doi:10.1029/2005JE002645. [Printed 112(E3), 2007].

Turcotte, D.L., Schubert, G., 2002. Geodynamics, second ed. Cambridge Univ. Press, Cambridge.

Turcotte, D.L., Willemann, R.J., Haxby, W.F., Norberry, J., 1981. Role of membrane stresses in the support of planetary topography. J. Geophys. Res., 86 (B5), 3951-3959.

Werner, S.C., 2008. The early Martian evolution-constraints from basin formation ages Icarus 195, 45-60.

Wieczorek, M.A., 2007. Gravity and topography of the terrestrial planets. Treatise Geophys. 10, 165-206. doi:10.1016/B978-044452748-6/00156-5.

Wieczorek, M.A., Zuber, M.T., 2004. Thickness of the Martian crust: improved constraints from geoid-to-topography ratios. J. Geophys. Res. 109, E01009. doi:10.1029/2003JE002153.

Wilson, L. Head III, J.W. 2002. Tharsis-radial graben systems as the surface manifestation of plume-related dike intrusion complexes: models and implications. J. Geophys. Res. 107 (E8), 5057. doi:10.1029/ 2001JE001593.

Wyatt, M.B., McSween, H.Y., 2002. Spectral evidence for weathered basalt as an alternative to andesite in the northern lowlands of Mars. Nature 417, 263-266.

Zuber, M.T., et al., 2000. Internal structure and early thermal evolution of Mars from Mars Global Surveyor. Science 287, 1788-1793. 